\title{
LA DORSAL ASUNCIÓN - RÍO GRANDE: UN ALTOFONDO REGIONAL ENTRE LAS CUENCAS PARANÁ (BRASIL, PARAGUAY Y URUGUAY) Y CHACOPARANAENSE (ARGENTINA)
}

\author{
EDUARDO A. ROSSELLO', GERARDO VEROSLAVSKY ${ }^{2}$, HÉCTOR DE SANTA ANA ${ }^{2,3}$, VI- \\ CENTE J. FÚLFARO ${ }^{4}$ \& CÉSAR A. FERNÁNDEZ GARRASINO ${ }^{5}$
}

\begin{abstract}
Resumen La Dorsal Asunción - Río Grande (DARG) es un accidente tectónico de primera magnitud que constituyó un altofondo regional responsable de la compartimentalización de la sedimentación post-Pérmico-Triásico de las cuencas Paraná (Brasil, Paraguay y Uruguay) y de la Llanura Chacoparanense (Argentina). El extremo septentrional de la DARG, en Paraguay, está representado por el Alto Asunción materializado por una ventana del basamento cristalino (Cratón Tebicuary) buzante hacia el SSE y orlado por secuencias sedimentarias paleozoicas y mesozoicas. Contrariamente, el extremo austral de la DARG, está constituido por el Alto de Río Grande, localizado en el Estado de Río Grande do Sul, Brasil; y está igualmente caracterizado por un asomo de basamento cristalino orlado por secuencias Paleozoicas y Mesozoicas, pero buzante hacia el NNW. El tramo intermedio, en los territorios de Argentina y Uruguay, está menos expuesto y exige una correlación regional mediante información de subsuelo. La DARG separa dos grandes ambientes depositacionales que corresponden a los siguientes ámbitos de la Cuenca Paraná, hacia el oriente, mejor expuesta y las diferentes cuencas sedimentarias cubiertas por la Llanura Chacoparanense, hacia el occidente. Por la disposición geográfica, cinemática y cronologia de su evolución, su origen puede correlacionarse con la tectónica convergente del Paleozoico superior que estructuró a las Sierras Australes de Buenos Aires (Argentina). Finalmente, la evaluación de la influencia de la DARG contribuye con la comprensión de los mecanismos tectosedimentarios que acusan las secuencias constituyentes de los rellenos de las cuencas de la Llanura Chacoparanense y Paraná.
\end{abstract}

Palabras claves: Tectónica, Cuenca Paraná, Cuencas Llanura Chacoparanense, Paleozoico-Mesozoico, América del Sur.

\begin{abstract}
THE DORSAL ASUNCIÓN - RIOO GRANDE: A REGIONAL UPLIFT BETWEEN THE PARANAं (BRAZIL, PARAGUAY AND URUGUAY) AND CHACOPARANENSE (ARGENTINA) BASINS The Dorsal Asunción-Rio Grande (DARG) is a first magnitude tectonic megastructure that constitutes a regional depositional uplift responsible for the partitioning of the postPermian-Triassic sedimentation of the Paraná (Brazil, Paraguay and Uruguay) and Llanura Chacoparanense (Argentina) basins. The northern end of the DARG, in Paraguay, is represented by the Asunción High materialized by an outcrop of the crystalline basement (Tebicuary Craton) plunging toward the SSE and fringed by Paleozoic and Mesozoic sedimentary sequences. Contrarily, the southern extreme of the DARG is constituted by the Rio Grande High, located in the Rio Grande do Sul State, Brazil; and it is equally characterized by an outcrop of crystalline basement fringed by Paleozoic and Mesozoic sequences, but plunging toward the NNW. The intermediate tract, in the territories of the Argentina and Uruguay, is less exposed and required a regional correlation by means of subsurface information. The DARG separates two huge tectonosedimentary environments that correspond to the adjacent Paraná Basin, toward the east, better exposed and the different sedimentary basins covered by the Llanura Chacoparanense, toward the west. On the basis of geographical disposition, kinematics and chronology of its evolution, the DARG's origin can be correlated with the convergent tectonics of the Late Paleozoic that structured the Sierras Australes of Buenos Aires (Argentina). Finally, the evaluation of the influence of the DARG contributes to the understanding of the tectonosedimentary mechanisms that exhibit the sequence constituting the infill of the basins of the Llanura Chacoparanense and Paraná.
\end{abstract}

Keywords: Tectonics, Paraná Basin, Chacoparanense Basin, Paleozoic-Mesozoic, South America.

INTRODUCCIÓN La delimitación y correlación de los depocentros que constituyen las cuencas Paraná, en Brasil y Paraguay, Norte en Uruguay, y de la Llanura Chacoparanense, en Argentina, ha planteado un gran desafio por su gran extensión, la escasez de afloramientos, la importante cubierta moderna que posee y la dificultad en establecer parámetros de correlación homogéneos entre los geólogos de los cuatro países en los que se distribuyen. $\mathrm{Al}$ respecto, uno de los primeros esfuerzos que involucró investigadores locales relacionados en este sentido fue la importante aproximación de correlación litocronoestratigráfca regional realizada por França et al. (1995).

Sin embargo, la caracterización morfológica y evolución de los depocentros receptores de la sedimentación paleozoica y mesozoica aún mantienen importantes indefiniciones, justamente en la zona de transición entre los dos grandes ambientes tradicionalmente definidos: la Cuenca Paraná, al Este (Fulfaro et al., 1982; Zalán et al., 1990; Milani, 1997), y las Cuencas de la Llanura Chacoparanense, al Oeste (Russo et al., 1979; Pezzi \& Mozetic, 1989; Chebli et al., 1999; Urien, 2003, entre otros).

De esta manera, el presente trabajo tiene como principal objetivo realizar una revisión morfoestructural y tectosedimentaria integral conjunta entre investigadores de los diferentes países donde se extiende la zona de transición entre los dos grandes dominios y remarcar la posición regional de la estructura de primer orden y dirección general NNW-SSE que parcialmente las separa.

Esta zona de transición se extiende casi paralelamente al Río Paraguay, desde el Estado de Mato Grosso do Sul (Brasil), hacia el Sur de Corumbá en dirección a la ciudad de Asunción y sus comarcas meridionales. Este rasgo geológico mereció su

1 - CONICET - Departamento de Ciencias Geológicas, Universidad de Buenos Aires, Pabellón II, Ciudad Universitaria, 1428 - BUENOS AIRES, Argentina. E-mail: rossello@gl.fcen.uba.ar

2 - Departamento de Evolución de Cuencas, Facultad de Ciencias, Universidad de la República. Iguá 4225. 11400 - MONTEVIDEO, Uruguay.

3 - ANCAP División Investigación y Desarrollo. Av. Lib. Gral. Lavalleja y Paysandú. № 1090. 11100 - MONTEVIDEO, Uruguay.

4 Departamento de Geologia Aplicada, Universidade Estadual Paulista, UNESP, Avenida 24A 1515, 13506-900, Rio Claro, SP, Brasil

5 - Universidad de Buenos Aires - GEODATOS S.R.L., BUENOS AIRES, Argentina. 
consideración desde los primeros trabajos exploratorios, a los que se han referido de distintas formas: Anticlinal central-paraguayo (Putzer, 1962); Umbral centro-paraguayo mesopotámico (Padula \& Mingramm, 1968); Arco de Asunción (Sanford \& Lange, 1960; Palmieri \& Velázquez, 1982); Arco Central Paraguayo - Arco de Asunción (Fulfaro et al. 1982); Alto Asunción - Corumbá (Urien \& Zambrano 1996). Por su parte, Harrington (1950), al referirse a la estructura geológica del Paraguay y la delimitación del borde occidental de la Cuenca Paraná, haciendo mención a los asomos precámbricos, reconoció casi explícitamente su existencia. Asimismo, fue considerado por Almeida (1967) como uno de los elementos tectónicos principales de la plataforma brasileña en relación con una estructura mayor que se continuaba hacia el Norte (la Faja Paraguay-Araguaia), la que a su vez delimitaba diferentes núcleos cratónicos.

La disposición del Alto Asunción y su prolongación austral ha motivado varios estudios por su influencia en la conformación de los depocentros aledaños (véanse detalles en França et al., 1995; Tankard et al., 1995; Milani, 1997; Chebli et al., 1989 y 1999; Fernández Garrasino et al., 2005, entre otros). Sanford \& Lange (1960) colocaron al Arco de Asunción como la estructura tectónica más destacada de la Cuenca Paraná, definiéndola como una extensa flexura de basamento que, con dirección Norte-Sur, atraviesa Paraguay y se extendería por el subsuelo argentino hasta la región del Río de la Plata. Tankard et al. (1995), indicaron que la prolongación austral del Arco de Asunción atravesaría la región central del territorio uruguayo y muestra incluso, una continuidad de toda esta megaestructura con el lineamiento Tantalite - Pofadder en Africa del Sur. Otros autores establecieron que la continuidad del Arco de Asunción hacia el sur encontraría al Arco Camilo Aldao, ya en el subsuelo de la cuenca de la Llanura Chacoparanense (França et al., 1995), mientras que Fulfaro et al. (1997) sugieren la existencia de dos brazos que se abren desde el Alto de Asunción, uno extendiéndose hacia el SE en dirección al Arco de Río Grande y otro hacia el S-SW hacia la Mesopotamia argentina.

Esta última alternativa había sido también sugerida por Fernández Garrasino (1992a y 1992b), a partir de los datos obtenidos del Pozo Nogoyá, perforado en la ciudad homónima de la Provincia de Entre Rios (coordenadas: 59,78957 LW y 32,3888 LS) a una cota de $79 \mathrm{~m}$ s.n.m y que alcanzó los $2080 \mathrm{~m}$ de profundidad $\sin$ salir de niveles paleozoicos superiores. Luego, reconoce que los rasgos estructurales que así lo indican sólo pueden ser seguidos hasta la porción austral de la provincia de Corrientes (Fernández Garrasino \& Vrba, 1999 y 2000).

En este trabajo, la continuación austral del Alto de Asunción se aborda en dos aspectos básicos: su existencia, disposición regional y su evolución tectónica. De esta forma, en este trabajo se analiza conjuntamente al Alto Asunción con el Alto Río Grande (Figura 1), considerándolos como segmentos constituyentes de un único accidente tectónico de primera magnitud que acusa rasgos morfotectónicos y consecuencias tectosedimentarias comunes a lo largo de la evolución fanerozoica. Por ello, se propone aquí su identificación como Dorsal Asunción - Río Grande (DARG) y se lo define como un altofondo regional responsable de la compartimentalización de los depocentros sedimentarios de las cuencas Paraná y de la Llanura Chacoparanense.

El rol activo en el control de la sedimentación fanerozoica es objeto de análisis, mostrándose diferentes elementos de juicio, mayoritariamente estratigráficos sobre la antigüedad de esta estructura como rasgo positivo que se remontaría por lo menos al Carbonífero inferior, y aún al Devónico, según algunas opiniones no carentes de fundamento (Fernández Garrasino et al., 2005). El control e incidencia de la DARG se verifica plenamente en la distribución de los depocentros post-permotriásicos a ambos lados de este accidente tectónico, por lo que es el objetivo principal la descripción de la geometría y origen de la DARG y su influencia en la distribución de las unidades volcanosedimentarias a partir de la visión regional que los autores tienen desde sus respectivos países.

Asimismo, se discute la incidencia de la DARG en la compartimentación y definición de la geometría de las unidades sedimentarias que componen el Sistema Acuífero Guaraní así como la implicancia que el modelo propuesto tiene para la exploración y explotación de las aguas subterráneas. Con este propósito, otros rasgos estructurales mayores son descriptos y analizados en función de su relación con la DARG y el control de los depocentros sedimentarios de las cuencas Paraná y de la Llanura Chacoparanense.

LA DORSAL ASUNCIÓN - RÍO GRANDE La DARG separa dos medios morfotectónicos diferentes: i) el Oriental, caracterizado por un ambiente con relieves marcados que se expresan en importantes afloramientos rocosos dominados por las coladas de la Formación Serra Geral, determinantes de serranías que superan los $1000 \mathrm{~m}$ de altitud; y ii) el Occidental, representado por planicies monótonas y extensas (Llanura Chacoparanense y Mesopotamia) constituidas por sedimentos fluvio-loéssicos modernos que cubren todos los registros paleozoicos y mesozoicos, los que sólo logran asomarse en las provincias de Corrientes y Misiones (Argentina) y en el Norte de Uruguay. La actual configuración morfológica de esa región meridional extensa de Sudamérica está pautada por los procesos tectónicos, magmáticos y sedimentarios mesocenozoicos; donde para la región Oriental, están particularmente ligados a la evolución del margen Atlántico mientras que para la región Occidental a la del antepaís del orógeno Andino.

Para una mejor descripción y caracterización de los principales rasgos geológicos y estructurales de la DARG, se la subdivide en los siguientes segmentos: i) septentrional, ii) austral, $y$ iii) intermedio.

Segmento septentrional El extremo septentrional de la DARG, se localiza en la región Oriental del Paraguay, y está representado en dos áreas del Alto de Asunción (Figura 1) en las que afloran el basamento cratónico (Clérici et al., 1986; Wiens, 1995): una situada al Norte, sobre la frontera con Brasil, denominada Subcratón del Río Apa y otra región más al sur, el Subcratón del Río Tebicuary constituidos por un mosaico de unidades con edades paleoproterozoicas (gneises y granitos), cinturones deformados en condiciones metamórficas mesoproterozoicos y secuencias plataformales neoproterozoicas (Figura 2). El Alto de Asunción a partir del asomo de basamento en el Subcratón Tebicuary muestra un buzamiento preferencial hacia el SSE y está orlado parcialmente por secuencias sedimentarias paleozoicas y mesozoicas que se adosan periclinalmente

Este segmento de la DARG se reconoce tanto por trabajos de geología de superficie como por datos de subsuelo obtenidos con fines petroleros. También, aportan los estudios de geofísica y perforaciones profundas realizados desde el Alto de Caacupu (en la región meridional del Paraguay Oriental), que se continúan al norte, por el Alto de Asunción, Bajo de San Pedro, Alto de Apa, Bajo de Río Verde - Coxim (Fulfaro \& Perinotto, 1996), hasta el cratón Amazónico en la región del Espolón Bodoqueña Spur (Gohrbandt, 1992), en territorios de Brasil (Estados de Matto Grosso y Mato Grosso do Sul). En relación con su continuidad continental hacia el Norte, Jones (1985) lo ha asociado con la denominada Faja Paraguaya como uno de los brazos de un punto triple ligado a una apertura oceánica finiproterozoica. Este contexto habría permitido el ingreso del mar al que se vincula la depositación de un conjunto de unidades marinas plata- 


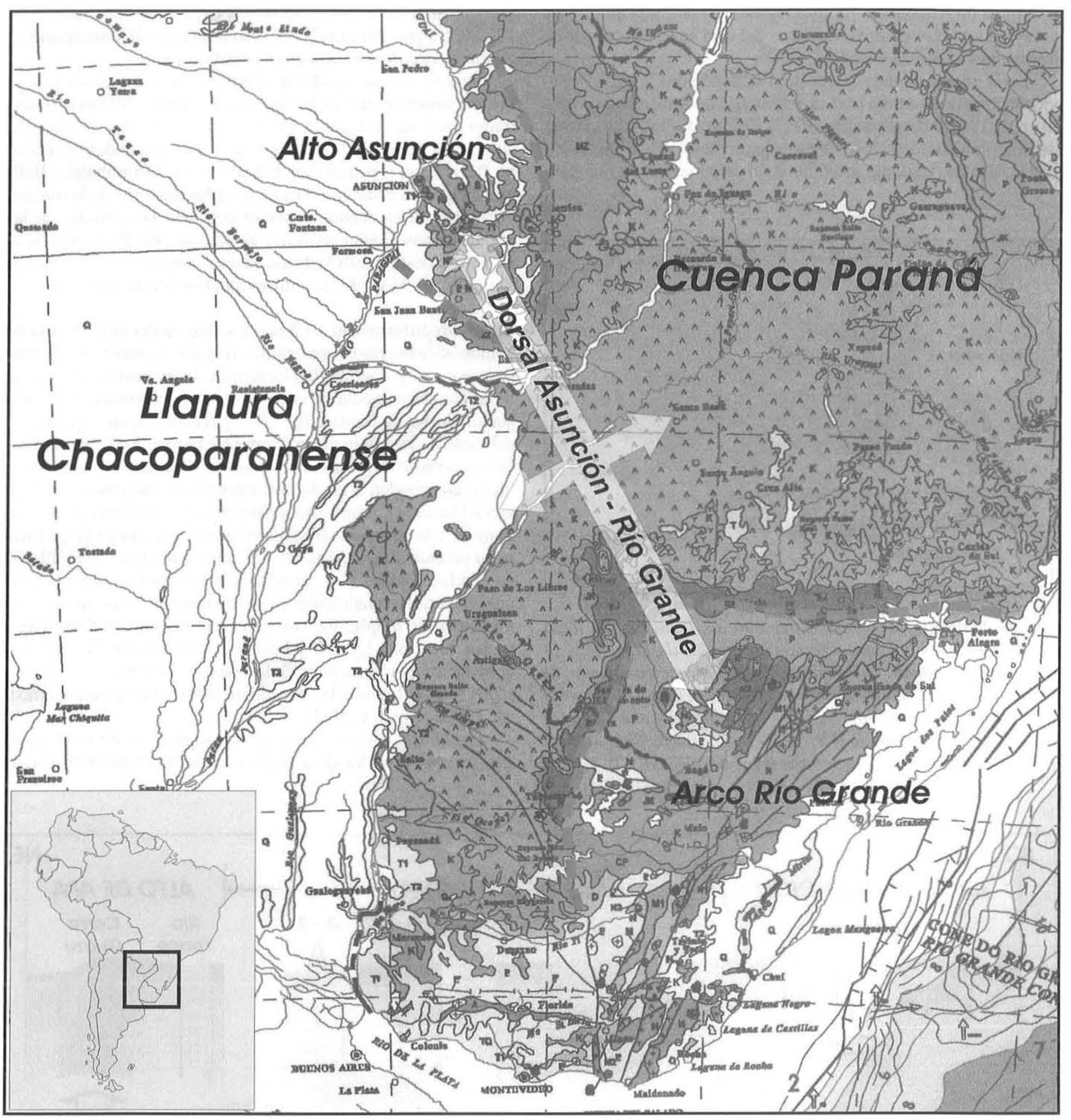

Figura 1. Esquema geológico regional y localización de la Dorsal Asunción - Río Grande entre la Llanura Chacoparanense y Cuenca Paraná (tomado del mapa geológico de América del Sur, UNESCO, 1995).

formales (Grupo Corumbá en Brasil y Grupo Paso Pindó en Paraguay) y que están preservadas en varias regiones meridionales y, particularmente, adosadas al Arco de Asunción.

Por otra parte, el basamento cratónico paraguayo ha sido afectado hacia finales del Proterozoico por un magmatismo representado en la Suite Magmática Caapucú que intruye, en la fase pos-tectónica del Ciclo Brasiliano, al subcraton de Tebicuary así como a las secuencias neoproterozoicas (Grupo Paso Pindó). Este evento magmático posee un carácter ácido y está constituido por rocas con varios niveles de emplazamiento (plutónicas, hipabisales y efusivas), principalmente de granitos gruesos a porfiríticos, pórfidos riolíticos y riolitas, de edad $\mathrm{Rb}$ /
Sr $531 \pm 5$ Ma. (Fulfaro, 1996).

Cabe señalar que en la región Oriental del Paraguay, aparece un conjunto de rocas alcalinas asociadas con las rocas paleozoicas y mesozoicas de la región del Arco de Asunción y relacionadas tectónicamente con estructuras extensionales (Figura 3). Comin-Charamonti et al. (1990), reconocen que este magmatismo, representado por decenas de cuerpos intrusivos que se extienden por un amplio intervalo de tiempo ( 240 a $36 \mathrm{Ma}$ ), se encuentra íntimamente asociado con la evolución tectónica del Arco de Asunción. Las litologías que representan este magmatismo son variadas, con mayor predominio de las rocas alcalinas silicáticas, a diferencia de las carbonatitas que se restringen a la 
provincia de Amambay. En esta región, se identifica un importante fallamiento regional a lo largo del cual se emplazan varias intrusiones alcalinas y básicas.

De la misma manera que el Bajo de San Pedro (Figura 3) sirvió de conexión marina para la Subcuenca de Apucarana (Fulfaro et al., 1982 y Bergamaschi, 1999), Fulfaro \& Perinotto (1996) definieron el Bajo de Río Verde - Coxin (separado del primero por el Alto de Apa) que actuó también de conexión marina para

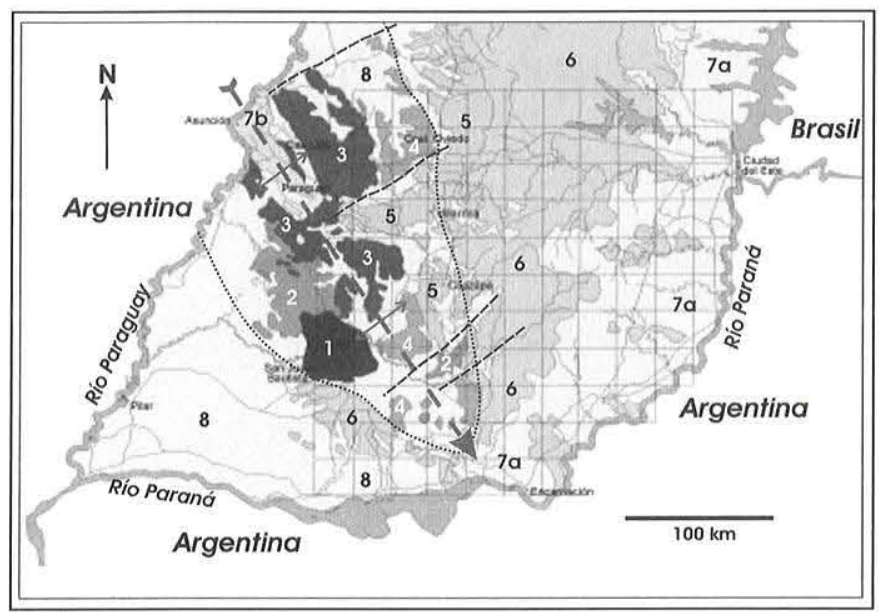

Figura 2. Bosquejo geológico del Alto de Asunción (en línea de puntos) sobre un mapa geológico parcial de Paraguay. 1) Intrusivos Tebicuary, 2) Precámbrico, 3) Paleozoico inferior, 4) Carbonífero, 5) Pérmico, 6) Formación Serra Geral, 7a) Cretácico-Fm. Palacios, 7b) Cretácico-Fm. A. Jara y 8) Cubierta cuaternaria (adaptado de Wiens, 1995). Las lineas discontinuas indican la posición de estructuras transversales NE-SW. los depósitos ordovícicos, silúricos y devónicos de la Subcuenca Alto de Garças. Pereira (2000) relacionó la posible presencia de este aulacógeno al lineamiento Transbrasiliano.

Otro factor que resalta la intensa actividad tectónica de la DARG septentrional es la ausencia de varias unidades litoestratigráficas de la Cuenca Paraná que tienen una distribución amplia por dentro de la misma. Una de estas unidades es el Grupo Passa Dois (formaciones Estrada Nova, Corumbataí e Iratí) que a pesar de estar ausentes en los afloramientos de la margen occidental de la cuenca se reconocen bien preservadas en las grandes fosas tectónicas como el Bajo de San Pedro donde el registro litoestratigráfico de los pozos Asunción 1 y 2 (Fulfaro \& Perinotto, 1994 y 1995) confirma su presencia (Figura 3).

Segmento intermedio La porción intermedia de la DARG no exhibe afloramientos importantes (Figura 1), razón por la cual su presencia y continuidad espacial solo es posible identificar indirectamente mediante correlaciones e información de subsuelo. Herbst \& Santa Cruz (1985) reconocen en superficie y subsuelo de la provincia de Corrientes (Argentina), una intercalación potente de areniscas y basaltos, de edad Juro-Cretácico, que corresponden a las formaciones Solari (areniscas) y Serra Geral (basaltos). Asimismo, dichos autores, admiten que por encima de esta sucesión volcanosedimentaria se apoya un paquete poco potente de areniscas gruesas que básicamente sólo afloran en dos localidades y se asimilan a la Formación Yerúa (Cretácico Superior). Igualmente, en el territorio de Misiones, poseen un desarrollo amplio los basaltos de la Formación Serra Geral y próximo a San Ignacio y Loreto existen asomos de areniscas conferibles a la Formación Solari de tonos rojizos claros y morados muy cohesionadas por silicificación (Fernández Garrasino, 1992a, 1992b y 1993).

Los afloramientos escasos en este segmento intermedio pueden interpretarse debido a la generación de la anticulminación

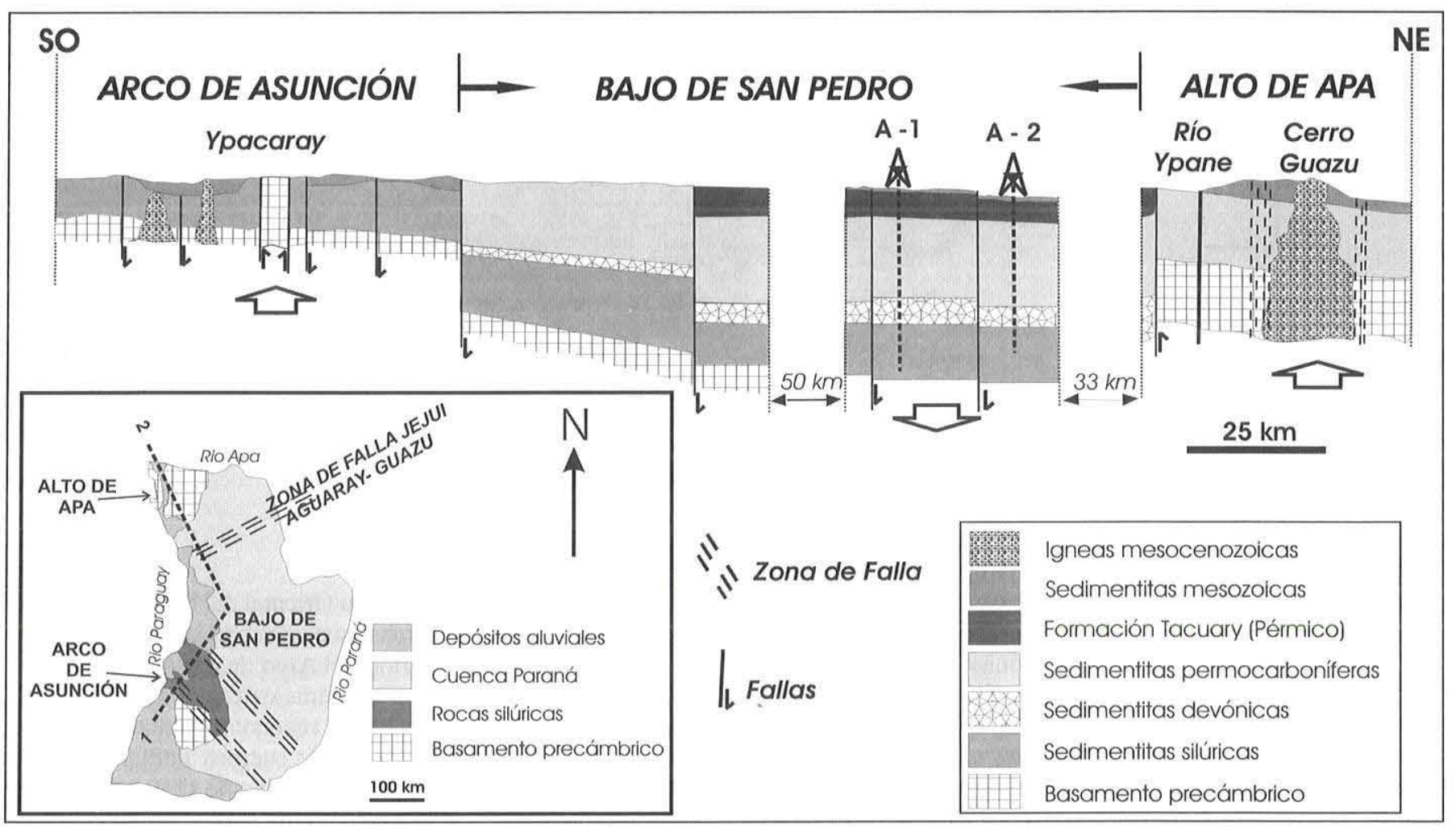

Figura 3. Rasgos estructurales del Alto Asunción, Bajo de San Pedro y Alto de Apa a partir de una sección a aproximadamente SO-NNE (simplificada de Fulfaro, 1996). A1: Pozo Asunción 1, A2: Pozo Asunción 2. 
de la DARG que adquiere una morfología de silla de montar que hace descender relativamente a las unidades aflorantes en los extremos. Esta geometría está remarcada también por los relevamientos gravimétricos regionales que exhiben anomalías de Bouguer dispuestas con dirección preferencial NW-SE que tienden a separar dos mínimos principales que corresponden a los depocentros de las cuencas Paraná y Chacoparanaense (Figura 4).

Esta estructura estaría directamente asociada con el desarrollo del denominado "Rift Central" de la Cuenca Paraná (graben Foz de Iguaçu - Araçatuba) en el subsuelo de los estados de San Pablo, Paraná, Santa Catarina y Río Grande do Sul (Milani, 2004). En este sentido, la prolongación SO del fallamiento extensional NE-SW que controló su margen austral podría continuarse a lo largo del Río Uruguay, ya que los cambios de espesores que tienen las unidades sedimentarias entre Uruguay y Argentina sugiere la presencia de una estructura regional ( $\mathrm{Fi}$ gura 5).

El otro fallamiento principal que delimita por el norte al Rift Central (Graben Paranhos - Xavantina) disecta al segmento septentrional en el Arco Asunción y estaria ligada a las estructuras que con dirección NE-SW controlaron las zonas de debilidad cortical que contribuyeron dando lugar a los pasajes marinos entre el océano Proto-Pacífico y el interior de la Cuenca Paraná durante el Paleozoico (Figura 2).

La disposición de esta estructura resulta llamativamente subparalela a la disposición del Hemigraben Las Breñas, entre las provincias de Chaco, Formosa y Santiago del Estero y los depocentros del norte de la provincia de Santa Fé y Rosario (Figura 6). En todos ellos, a partir de información de subsuelo (sísmica 2D y pozos exploratorios), se caracteriza la existencia de secuencias paleozoicas muy potentes. En particular, en el Hemigraben Las Breñas, se reconocen secuencias del Paleozoico Inferior y posiblemente Precámbrico asociadas con un gran fallamiento normal de crecimiento sobre su margen occidental (Pezzi \& Mozetic, 1989; Chebli et al., 1999).

La interrelación de este fallamiento extensional con la DARG adquiere importancia por sus implicancias en la evolución de la

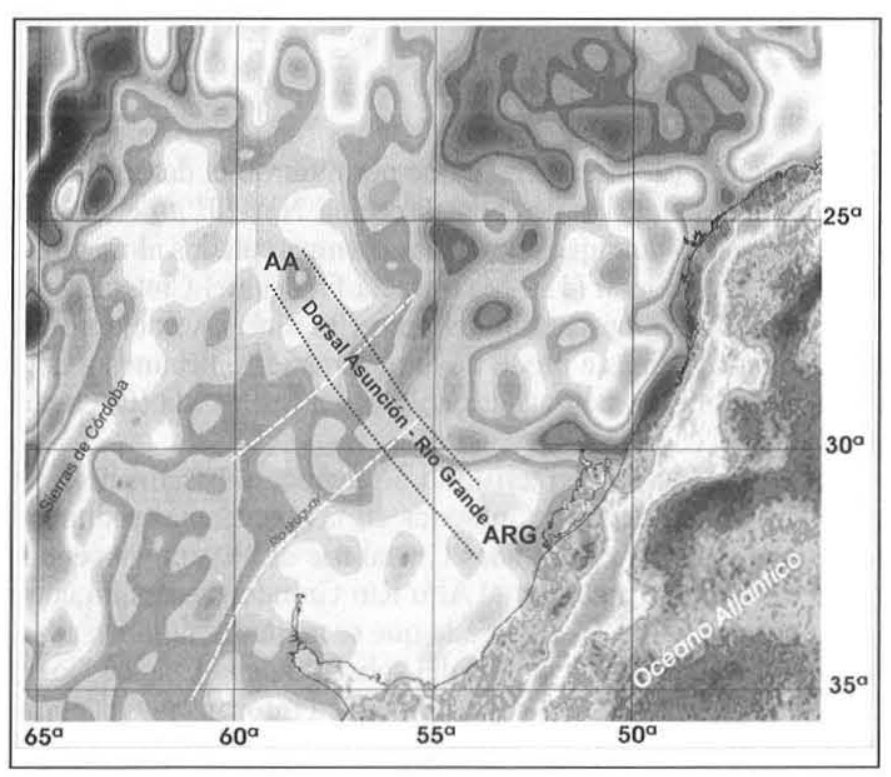

Figura 4. Mapa regional de anomalias de Bouguer donde los tonos grises obscuros indican valores máximos y los grises claros mínimos (tomado de www.itis-molinari.mi.it/Gravity) AA: Alto Asunción, ARG: Alto Rio Grande. Lineas discontimuas blancas indican estructuras transversales $N E-S W$ subordinadas.

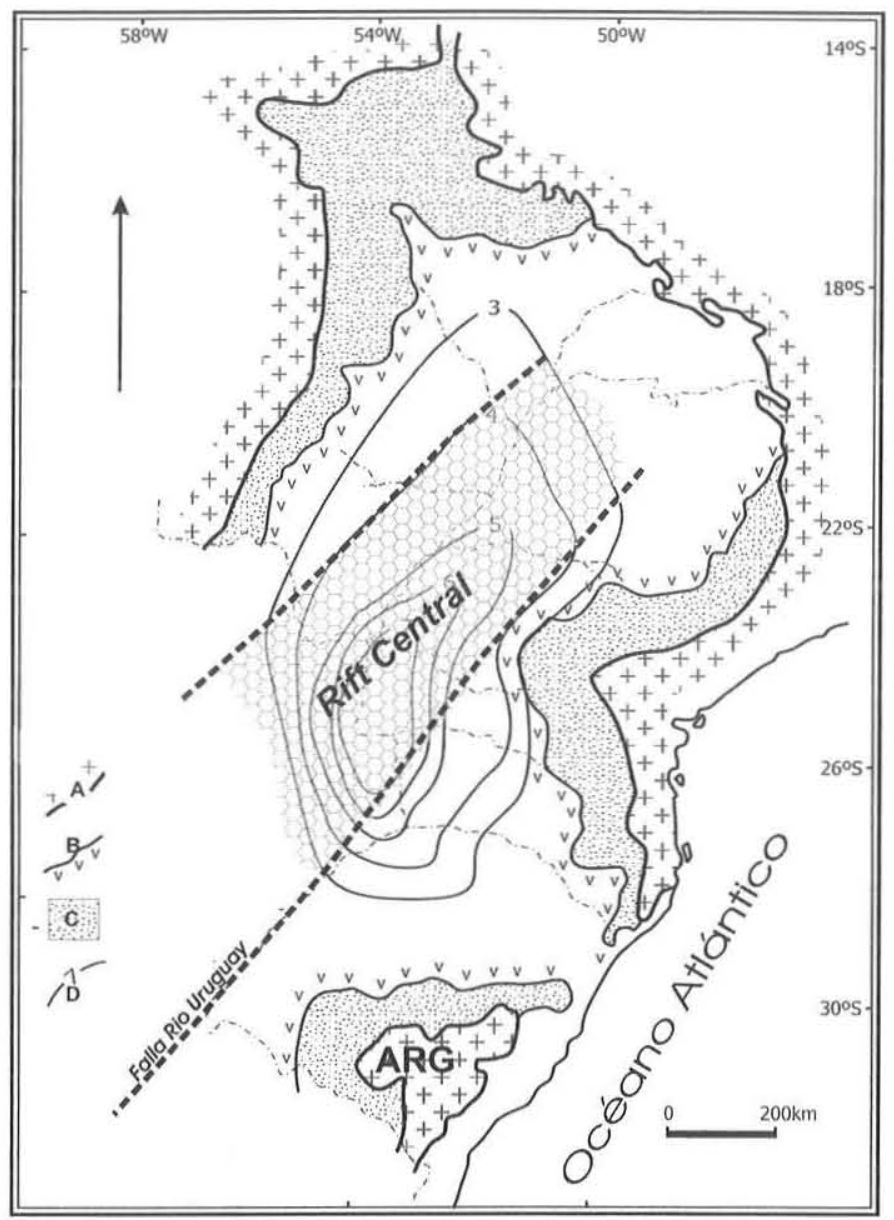

Figura 5. Esquema del Rift Central de la Cuenca Paraná y otros rasgos estructurales (Falla del Rio Uruguay). A: Borde de basamento, B: Borde de basaltos, C: Afloramientos sedimentarios y D: isópacas totales del relleno en $\mathrm{km}$ (Modificado de Zalan et al., 1990, Milani, 2004).

sedimentación paleozoica y mesozoica así como en el control de aspectos hidrogeológicos. Esto se base en que su funcionamiento parece controlar el depocentro acumulativo de las cuencas Paraná y Chacoparanense y particularmente el desarrollo de las unidades sedimentarias que conforman el Sistema Acuífero Guarani (Grupo Rosario do Sul y formaciones Piramboia, Botucatu, Misiones, Palacios, etc.) a los cuales podrían incorporarse los mayores espesores del magmatismo Serra Geral que también coinciden estos depocentros.

Segmento austral El extremo austral de la DARG, representado por el Arco Río Grande, localizado en el Estado de Río Grande do Sul, está caracterizado por un basamento precámbrico que se denomina Escudo Sul-Rio-Grandense (Figura 7). Esta unidad está afectada por un magmatismo plutónico calcoalcalino (700 Ma), y sucedido por un volcanismo y plutonismo shoshonítico de $600 \mathrm{Ma}$ y otro ácido alcalino de $580 \mathrm{Ma}$ (Chemale Jr., 2002).

El Arco Río Grande tiene su eje dispuesto con dirección preferencial NW-SE, de manera que coincide con las estructuras precámbricas y eopaleozoicas, las que a su vez se reconocen en superficie y subsuelo en la fuerte estructuración tectónica del noroeste del territorio uruguayo.

El Arco Río Grande está orlado periclinalmente por secuencias paleozoicas y mesozoicas que inclinan en su porción central hacia el NNW. Durante el Mesozoico, estuvo sujeto a esfuerzos 


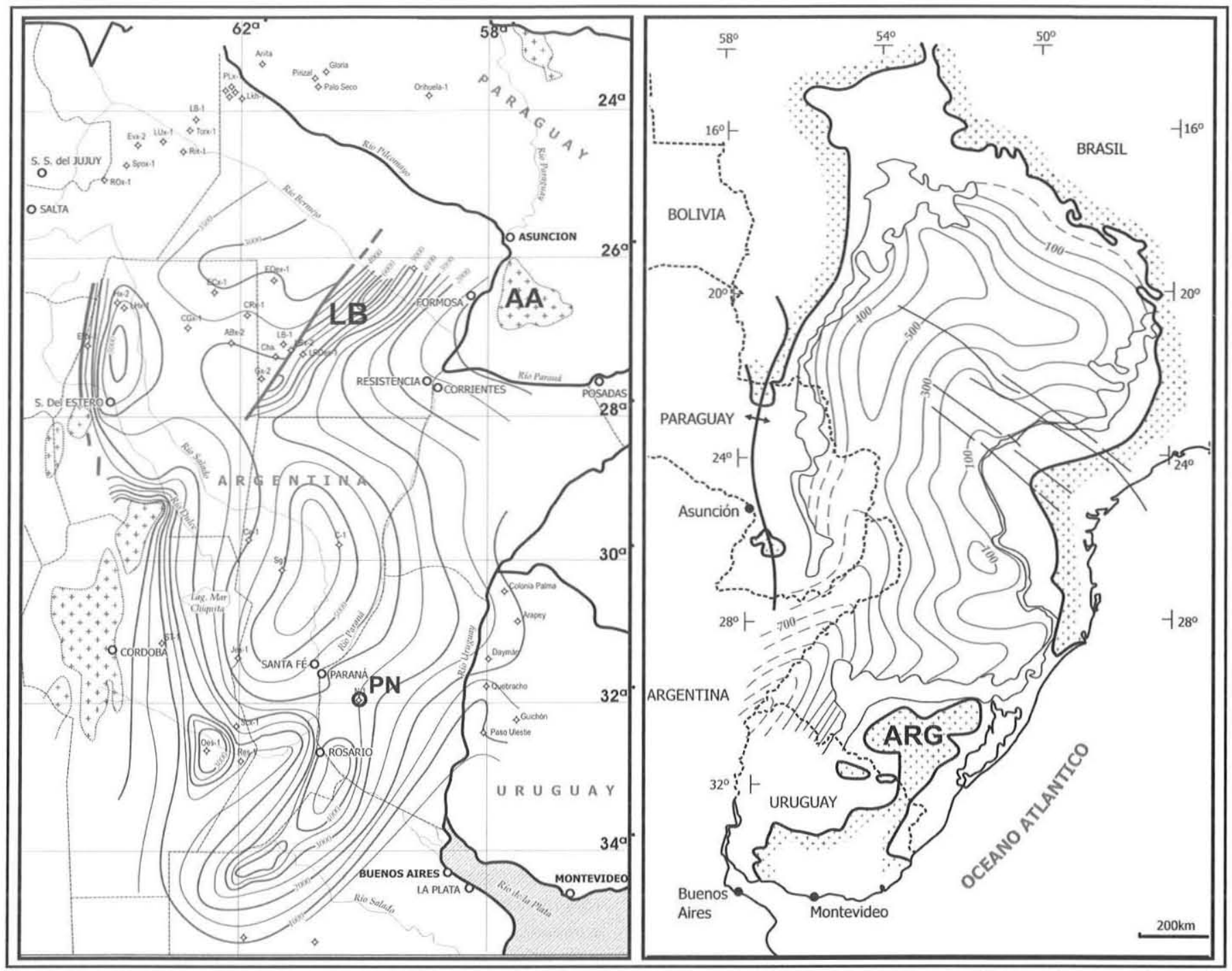

Figura 6. Izquierda: Isópacas totales acumulativas a partir de información sísmica 2D y pozos exploratorios que expresan una disposición preferencial de los depocentros en dirección NE-SW (tomada de Pezzi \& Mozetic, 1989). LB: Hemigraben Las Breñas, PN: Pozo Nogoyá. Derecha: Isópacas del Mesozoico sedimentario acumulativo de Grupo Rosario do Sul, y formaciones Piramboia, Botucatu, Misiones, Tacuarembó, Buena Vista (modificado de Zalan et al., 1990).

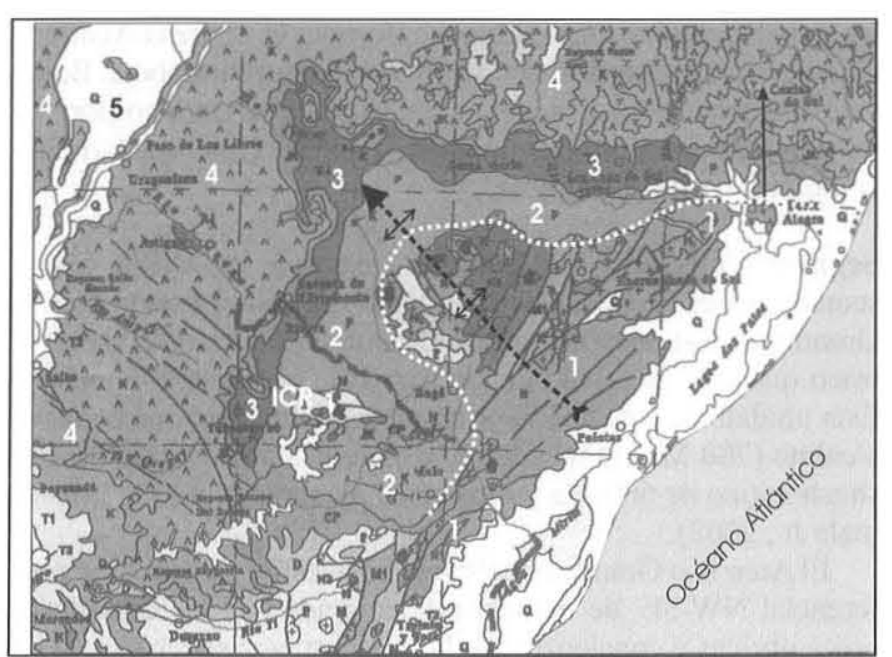

Figura 7. Bosquejo geológico del Arco Río Grande. 1) Basamento cristalino, 2) Paleozoico inferior, 3) Paleozoico superior; 4) Mesozoico y 5) Cenozoico. ICR: Isla Cristalina Rivera (tomado del mapa geológico de América del Sur, UNESCO, 1995). transcurrentes (transtensivos?) que permitieron el desarrollo de fallamientos extensionales con dirección NW-SE asociadas al emplazamiento de diques de diabasas emparentados al magmatismo de Serra Geral (130 Ma). Hacia finales del Cretácico, se registra en la región central del arco (Piratini) un conjunto de intrusiones alcalinas a modo de diques máficos alcalinos y chimeneas fonolíticas con edades en torno a los $80 \mathrm{Ma}$ (Chemale Jr., 2002).

Más hacia el Sur, en territorio uruguayo, el basamento asoma a través de "ventanas" abiertas en las secuencias sedimentarias que constituyen las Islas Cristalinas de Rivera y Aceguá. Estas estructuras, paralelas al Alto Río Grande, poseen un control morfotectónico NW marcado que se reconoce también en la estructuración de bajos y altos del subsuelo de la Cuenca Norte Uruguaya (De Santa Ana et al., 2006). La información disponible en territorio uruguayo permite caracterizar la geometría de la interfase entre el basamento cristalino y del relleno sedimentario pre- Pérmico y la de los eventos depositacionales permotriásicos, la influencia de los cuerpos intrusivos jurocretácicos así como la deformación tectónica previa a ese magmatismo (De Santa Ana et al., 2001). De este modo, se logra identificar y correlacionar a través de la información sísmica el conjunto de 
estructuras basamentales (altos y bajos) definidas por la gravimetría que muestran un control NW y que se consideran como parte integrante de la estructura de la DARG (Figura 8).

Las señales sísmicas asociadas a las unidades sismoestratigráficas permocarboniferas muestran flexuras en los reflectores principales y secundarios indicativos de la existencia de pliegues en niveles sedimentarios dispuestos en trenes de dirección NW-SE y E-W, con un espaciamiento regular de los ejes de plegamiento del orden de 20 a $30 \mathrm{~km}$. Particularmente, la Línea sísmica $\mathrm{N}^{\circ} 6$ dispuesta con dirección NNE, permite identificar dentro de estos niveles charnelas anticlinales estrechas que se contrastan con sinclinales en forma de cubetas de fondo plano y mucho más extensas (Figura 9).

Se observa que los anticlinales son relativamente simétricos, con planos axiales verticales, y que se asocian a numerosas fallas inversas de alto ángulo y pequeño rechazo que involucran la interfase del basamento cristalino con el relleno paleozoico. Estas fallas poseen una tendencia general a inclinar de mane- ra que convergen hacia las porciones profundas del núcleo de los anticlinales. El fuerte ángulo y su localización estratigráfica sugieren la posibilidad de inversión compresional de fallas normales asociadas a la sedimentación de unidades paleozoicas prepérmicas o eopérmicas. Asimismo, las líneas sísmicas muestran que los reflectores poseen una tendencia a converger hacia las charnelas de los pliegues y divergen hacia los depocentros lo que indican la contemporaneidad entre la sedimentación y la generación de las estructuras compresivas (Figura 9). De este modo, se pueden reconocer rasgos sismotectónicos típicos de plegamiento de crecimiento (growth-folding), al menos, para varios tramos sedimentarios atribuidos a los depósitos pérmicos que materializan las unidades sismoestratigráficas permocarboníferas.

Además, en las porciones cuspidales del ciclo depositacional continental permotriásico de la Cuenca Norte uruguaya se reconocen truncamientos de los reflectores secundarios intrasecuenciales en posiciones próximas a los anticlinales que eviden-

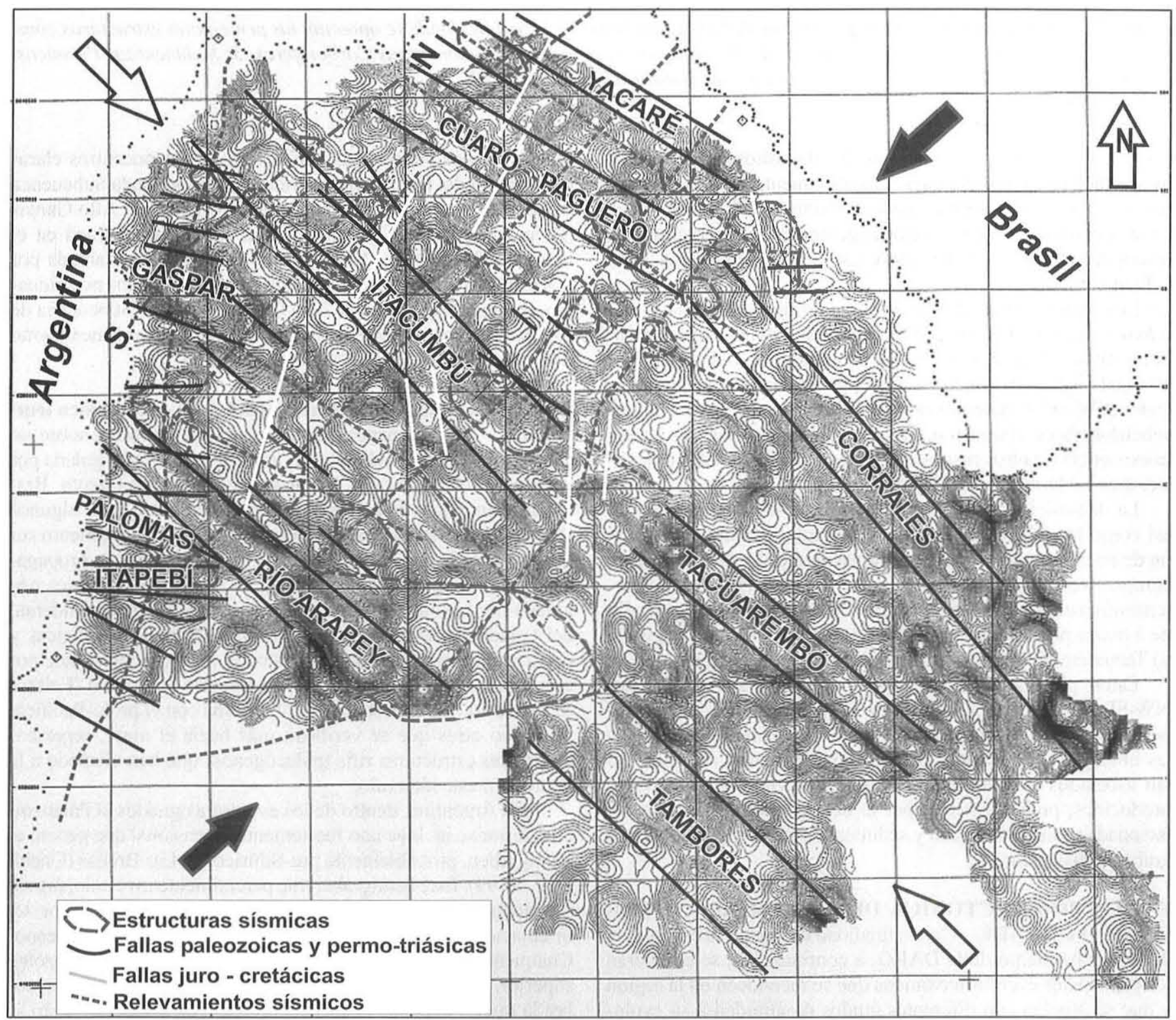

Figura 8. Gravimetria residual de la Cuenca Norte de Uruguay donde se aprecian trenes de estructuras compresivas dispuestas $N W$, algunas de ellas comprobadas por relevamientos sísmicos (Lineas rojas discontinuas). Las flechas negras indican la posición del Esfuerzo Principal Máximo (o, Permo-triásico y las flechas blancas indican la posición del Esfuerzo Principal Máximo ( $\left.\sigma_{\nu}\right)$ Mesozoico (tomado de De Santa Ana et al., 2001). SN indica la posición de la Línea Sísmica $N^{\circ} 6$ (Figura 9). 


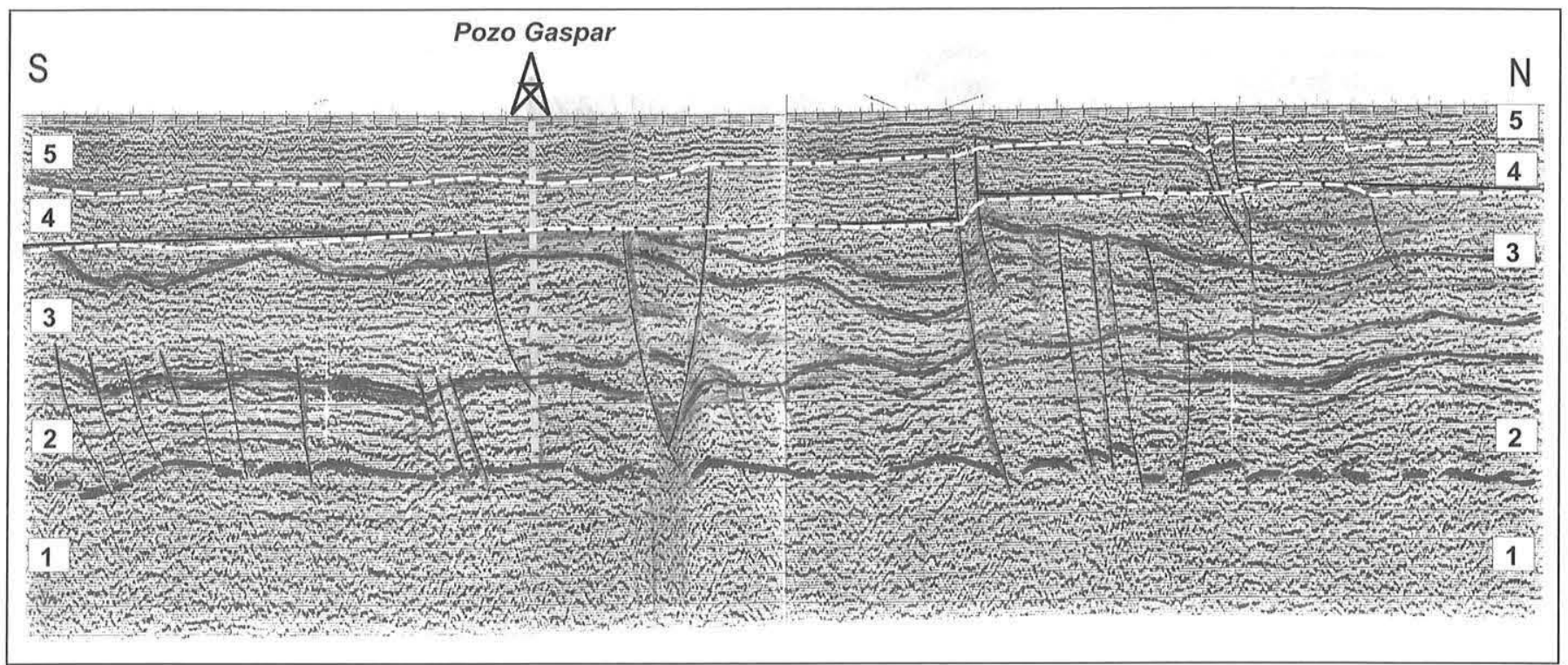

Figura 9. Sección sísmica $N^{\circ} 6$ características de la Cuenca Norte de Uruguay donde se aprecian las principales estructuras compresivas (tomado de De Santa Ana et al., 2001). 1: Basamento cristalino, 2: Sedimentitas Carboniferas, 3: Sedimentitas Pérmicas, 4: Areniscas Jurocretácicas y 5: Basaltos cretácicos. Localización en Figura 8.

cian las relaciones discordantes con los depósitos sedimentarios jurocretácicos subhorizontales. Contrariamente, en los depocentros sinclinales, la geometría de los reflectores son de naturaleza paraconcordantes. Estas relaciones geométricas observadas corresponden a la discordancia entre las formaciones Buena Vista y Tacuarembó.

Los mapas gravimétricos de Bouguer muestran igualmente máximos (altos) de formas más estrechas y agudas que los mínimos (bajos) lo que conforma un conjunto de máximos de unos 10 mgal dispuestos alineados a lo largo de direcciones preferenciales NW-SE y materializados en altos con diseños en planta subelipsoidales. Asimismo, la información gravimétrica revela la existencia de otros rasgos estructurales subordinados con posiciones sublatitudinales (Figura 8).

La disposición NW-SE preferencial de los ejes de pliegues así como las fallas inversas de alto ángulo denotan la actuación de un campo de esfuerzos regional subhorizontal de carácter compresivo dispuesto con dirección NE-SW. Esta tectónica determinó en el sector centro-oeste de la Cuenca Norte el desarrollo de 3 trenes principales de pliegues: i) Corrales - Cuaró Paguero; ii) Tacuarembó - Itacumbú, y iii) Tambores - Río Arapey

Estos plegamientos dispuestos con ejes subhorizontales NW-SE afectaron invariablemente a las unidades sedimentarias pérmicas e involucran parcialmente al basamento cristalino y a las unidades pre-pérmicas o pérmicas tempranas. Además, están asociados a fallamientos contemporáneos subordinados y producidos, probablemente, por la inversión de estructuras relacionadas con la extensión y sedimentación en antiguas fosas o graben paleozoicas.

EVOLUCIÓN TECTÓNICA DE LA DORSAL ASUNCIÓN-RIO GRANDE Con la finalidad de ajustar la cronología del funcionamiento de la DARG, a continuación, se enumeran los principales eventos tectónicos que se reconocen en la región y que se asocian con diferentes grados de afinidad a su evolución. Al respecto, Williams (1995) esquematiza en a traves de diferentes secciones conceptuales el comportamiento del Alto Asunción a lo largo de toda su historia tectónica (Figura 10).

La Cuenca Paraná, en territorio brasileño, ha sido recientemente descripta, al menos para el Siluro-Devónico, como cons- tituida por dos subcuencas con sus propios depocentros claramente definido. Una, la más meridional, denominada Subcuenca Apucarana, y otra más septentrional Subcuenca de Alto Garças (Bergamaschi, 1999; Pereira, 2000). La Cuenca Paraná en el intervalo Ordovícico - Silúrico tuvo su evolución marcada por dos estilos o comportamientos estructurales distintos posicionados al norte (Subcuenca de Alto Garças) y al sur (Subcuenca de Apucarana) de una zona estructural definida por el Lineamiento de Guapira (en esa época "Alto de Guapiara").

\section{Eventos tectónicos del Proterozoico tardío - Paleozoico tem-} prano. La Subcuenca de Alto Garças, emplazada sobre un substrato cratónico, más estable, tuvo su subsidencia guiada por sucesivas reactivaciones transtensivas del Lineamiento Brasiliano, sumado a la sobrecarga sedimentaria. Si bien algunos autores han sostenido que la subsidencia del compartimento sur (Subcuenca de Apucarana) ha sido gobernada por la propagación hacia el interior del continente de la flexura litosférica originada por la sobrecarga tectónica junto a la margen occidental del Gondwana (Bergamaschi, 1999). Evidencias geológicas y estructurales muestran que la conexión marina responsable por esta sedimentación fue a través del Bajo de San Pedro (Fulfaro \& Perinotto, 1996). Esta conexión marina con el proto-Pacífico, así como otras que se verifican más hacia el norte, representa grandes estructuras rifts (aulacógenos) que han afectado a la DARG en este intervalo.

Para Argentina, dentro de los eventos asignados al Paleozoico inferior se incluye uno fuertemente extensional que generó el hemigraben, probablemente pre-Silúrico, de Las Breñas (Chebli et al., 1999). Este hemigraben fue parcialmente invertido, previo a la depositación de los sedimentos del Paleozoico superior. La orientación de esta fosa es paralela al posterior alto PampeanoChaqueño, que se elevó antes de la depositación del Paleozoico superior, causando el acuñamiento de la secuencia inferior, sobre la que se deposita la secuencia paleozoica superior. Esto se puede vincular con la distensión finiproterozoica a cámbrica que se visualiza a lo largo de la DARG, ya sea con la conformación de estructuras extensionales en torno al Alto Asunción así como al Río Grande - Islas Cristalinas de Rivera y Aceguá. Estos procesos extensionales sublatitudinales generalizados generaron un 

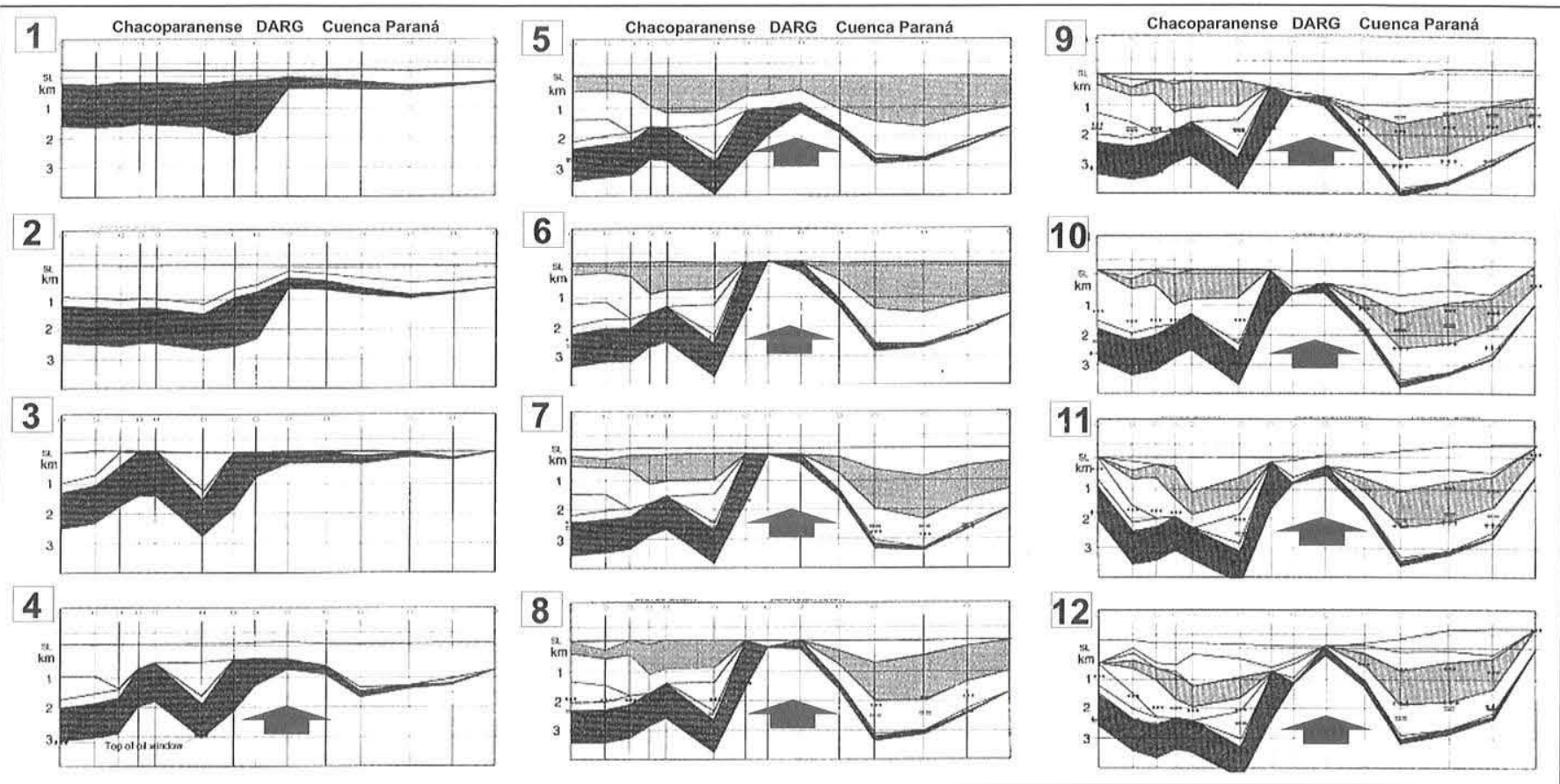

Figura 10. Secciones esquemáticas sublatitudinales a través del Alto Asunción. (simplificado de Williams, 1995). 1: Silúrico (408 Ma.), 2: Devónico (380 Ma.), 3: Tardio Devónico (340 Ma.), 4: Carbonífero (290 Ma.), 5: Pérmico (250 Ma.), 6: Discordancia Tardio Pérmico (230 Ma.), 7: Triásico (210 Ma.), 8: Discordancia (140 Ma.), 9: Serra Geral (115 Ma.), 10: Discordancia (98 Ma.), 11: Cretácico (67 Ma.), 12: Presente (0 Ma.). La flecha negra ascendente indica levantamientos de la DARG.

conjunto de cuencas con rellenos volcanosedimentarios con esa disposición tales como Las Breñas - Argentina, Bacia Camaqua - Brasil (Chebli et al., 1999) y cuenca de Barriga Negra - Uruguay.

Por lo tanto, se puede expresar que la DARG operó como un alto que limitó la sedimentación a partir de estructuras que se disponen sublatitudinalmente con un altofondo basamental y que permitieron un ingreso del mar más restringido hacia la porción brasileña de la Cuenca Paraná a partir de un pasaje oceánico.

Eventos tectónicos del Paleozoico tardío al Mesozoico temprano. Estudios sísmicos, gravimétricos, fotogeológicos y de campo en la porción paraguaya de la Cuenca Paraná revelaron fallamientos en bloques, grandes traslapamientos sedimentarios y un paquete sedimentario de más de 5000 metros de potencia total lo que conduce a una necesaria reformulación de la geometría de la cuenca (Redmond, 1979). Mapas gravimétricos regionales de Bouguer son consistentes con los datos sísmicos y de superficie. Por otro lado, dos grandes levantamientos pretriásicos, visibles en imágenes satélites constituyen domos con núcleos cristalinos. La cuenca es ligeramente asimétrica con un flanco occidental más pronunciado cuya deformación suave puede ser atribuida a la actividad conjunta del Arco de Asunción y el Sinclinal de Torres (Fulfaro \& Perinotto, 1996).

Posteriormente, las compañías Pecten - Occidental Trend realizaron dos pozos: Asunción 1 (1981) con una profundidad final de 3223 m y Asunción 2 (1982) con una profundidad final de 2985,9 m situados a lo largo de la DARG que confirmaron las secciones geológicas de Redmond (1979) y que fueron expuestas con mayor detalle por Fulfaro \& Perinotto (1996). Estos trabajos señalaron al Bajo de San Pedro situado periféricamente a los altos de Caacupu, al sur, y el Alto de Apa, al norte, como un aulacógeno que corta el Arco Asunción y sirve como conexión marina para las secuencias ordovícico-silúrico y devónica.
La región Oriental del Paraguay presenta características estructurales propias con las direcciones principales dominantes NS y NW-SE, y secundariamente, E-W. Las direcciones N-S corresponderían al evento tectónico más antiguo, ocurrido durante la evolución del ciclo orogénico Brasiliano, asociado con la intrusión de masas graníticas. Las direcciones NW-SE parecen estar relacionadas genéticamente a la apertura del Océano Atlántico durante el Mesozoico, con una mayor evidencia radicada en la megaestructura localizada en la parte centro-oriental del país. Las direcciones NE-SW son consideradas como correspondientes o asociadas con eventos regionales que ocurren en la periferia del basamento durante la fase tardía del ciclo Brasiliano.

Según este patrón tectónico, esta porción del Paraguay pasa a ser controlada por los diversos eventos tectonomagmáticos, predominantemente alcalinos del Cretácico - Terciario que afloran en las inmediaciones de Asunción como Formación Ñemby, cuya última actividad de las múltiples intrusiones de rocas ultra alcalinas acusan edades de 61 a 39 Ma (Fernández, 1992). Estas rocas aparecen en forma de cuerpos intrusivos y diques que afectan sedimentos rojizos (Formación Patiño), no muy bien consolidados representantes del evento de sedimentación postrift de Asunción. Estas rocas pertenecen a asociaciones petrológicas complejas que reúnen: i) nefelinitas oscuras de grano fino y levemente porfiríticas y portadoras de fenocristales de olivino con dimensiones de aproximadamente $2 \mathrm{~mm}$, afines petrológicamente con ambientes extensionales y ii) adakitas con tendencia sódica con nódulos de naturaleza mantélica poseen composición variable de lherzorlitas a dunitas, asociadas con ambientes de tipo subducción. Los contextos tectonomagmáticos diferentes expresados por estas litologías vinculadas con la DARG incrementan la necesidad de mayores explicaciones.

Por otro lado, Riccomini \& Fernández Velázquez (1999) estudian superficies estriadas relacionadas con la acción glacial neopaleozoica sobre el Alto Asunción que sugieren un área de 
aporte de hielos situados hacia el Sur-Sudeste de la Cuenca Paraná. Estos datos no resultan consistentes con un centro de proveniencia glacial localizado sobre el Alto Asunción, tal como lo han propuesto otros autores (Crowell \& Frakes, 1975; Santos et al., 1996). Esta sería otra evidencia indirecta de la presencia de este alto fondo en estos tiempos. La inversión antes citada, se reactivó al final del Paleozoico superior, plegando levemente esa secuencia tal como ocurre mucho más intensamente con unidades contemporáneas de las Sierras Australes de Buenos Aires (véanse entre otros: Cobbold et al., 1991; Rossello et al., 1997). En el borde norte de las Sierras Pampeanas Orientales, se reconoce también un episodio transpresional antes del Mesozoico, que deformó transpresionalmente a las secuencias paleozoicas. Estas estructuras tienen una orientación preferencial ENE-WSW, y están limitadas por fallas inversas de alto ángulo. Igualmente, los altos de Rincón-Caburé, Laboulaye, Saira, Camilo Aldao y Junín-Las Cañas, que compartimentalizan los diferentes depocentros paleozoicos de la Llanura Chacopampeana se elevaron antes del Neocomiano, facilitándose la erosión de su cobertura paleozoica superior (Chebli et al., 1999).

La Isla Cristalina de Rivera del Uruguay (Figura 7) fue una porción positiva durante la depositación de la Formación San Gregorio, ya que controló el ingreso de los lóbulos glaciares, se hundió paulatinamente hasta ser el principal depocentro durante la depositación del Pérmico de las formaciones Iratí y Mangrullo (portadoras de esquistos bituminosos) para luego mostrar hacia finales del Pérmico - inicio del Triásico (Formación Buena Vista) un ascenso progresivo. Como la distribución del mar Irati-Mangrullo está limitado por el oeste (Oelofsen \& Araújo, 1987) coincidentemente con la posición estimada de la DARG se puede asociar al Pérmico Superior (Kunguriano) ese levantamiento, ya que el mar Palermo - Fraile Muerto si está presente hacia el oeste en Argentina y Uruguay.

La elaboración de la información estructural y las interpretaciones tectónicas realizadas permiten reconocer en la Cuenca Norte de Uruguay la existencia de una tectónica paleozoica tardía de tipo compresional, tal como ocurre en las Sierras Australes de Buenos Aires (Cobbold et al., 1991; Rossello et al., 1997; López-Gamundí \& Rossello, 1997). Además, son concomitantes con la depositación del Grupo Pillahuincó (López-Gamundí et al., 1995) y otras unidades litoestratigráficas contemporáneas preservadas en algunas porciones del subsuelo de la llanura Chacopampeana de Argentina (Chebli et al., 1999).

Eventos tectónicos Meso-Cenozoicos. El desmembramiento extensional generalizado que observó el continente Gondwana a partir del Jurásico tuvo como consecuencia la separación de África y Sudamérica reflejándose en la generación de cuencas de rifts periféricos a la porción austral de la comarca estudiada (Cuenca del Salado, Cuenca Santa Lucía, Cuenca Merín - Pelotas, Cuenca Macachín, etc.). Además, esta extensión generalizada está remarcada por el emplazamiento de diferentes tipos de coladas, filones capa, diques y cuerpos subvolcánicos de naturaleza preferencialmente alcalina. Entre ellos, se destacan las coladas basálticas de la Formación Serra Geral (Uliana \& Biddle., 1988; Peate, 1997) que observan desde potencias máximas del orden de los $1.200 \mathrm{~m}$ en el litoral argentino-brasileño hasta desaparecer progresivamente a medida que se avanza hacia el oeste en las inmediaciones de las provincias argentinas de Córdoba, Chaco, Santiago del Estero y Buenos Aires (Figura 6).

Como consecuencia de la acción de los últimos eventos tectónicos debidos a la convergencia Andina, los principales depocentros cretácicos de la porción centro-occidental de Argentina están totalmente cubiertos por una carpeta potente y continua de sedimentos loéssicos cuaternarios (Uliana \& Biddle, 1988; Malumián et al., 1983; Chebli et al., 1999). De esta manera, el conocimiento geológico de estos volúmenes sedimentarios está determinado prácticamente por los trabajos de exploración de hidrocarburos.

En este sentido, los trabajos realizados en las últimas décadas han proporcionado relevamientos sísmicos y algunos sondeos exploratorios que permiten adquirir nuevos datos que facilitan el ajuste de las interpretaciones realizadas. Sin embargo, si se analizan en conjunto todos los depocentros continentales cretácicos localizados en la porción centro - occidental de Argentina y se integra la información de subsuelo en perfiles regionales sublatitudinales, se pueden interpretar (a pesar del carácter discontinuo de los datos disponibles), fajas submeridianales anchas que expresan distintos ambientes geotectónicos que han controlado su sedimentación continental (Rossello \& Mozetic, 1999).

El origen de esta zonación de faja de depocentros, está temporoespacialmente asociado a la creación del Océano Atlántico (Urien et al., 1981 y 1995; Rossello \& Mozetic, 1999) ya que podría expresar una extensión localizada intracontinental abortada hacia fines del Cretácico, como es el ejemplo de la Cuenca General Levalle (Webster et al., 2004). Este rasgo habría constituido un corredor transcontinental que pudo haber conectado los océanos Pacífico y Atlántico en tiempos cretácicos superiores (Rossello \& Lopez de Luchi, 2005) y actuado como nivel de base regional para el control de la sedimentación continental del Grupo Baurú en la Cuenca Paraná.

Sobre esta faja pueden reconocerse rasgos transcurrentes (según los criterios de Christie-Blick \& Biddle, 1985; Nielsen \& Sylvester, 1995), a partir de la particular disposición en planta y perfil de la arquitectura externa y estructuras de los rellenos volcanosedimentarios con respuesta sísmica (Webster et al., 2004).

Por su parte en Paraguay, la DARG se asocia con el emplazamiento de intrusivos alcalinos del Cretácico inferior en el Alto Asunción. Además, se reconocen efusivos terciarios que también se vinculan con la dinámica de esa región, tales como Formación Ñemby (Sonoki \& Garda, 1988) que se relacionan con un rifting (Figura 2).

Como resultado de la convergencia originada por la subducción de la placa oceánica de Nazca debajo de la continental de Sudamérica en una dirección general ENE-WSW durante los últimos $49 \mathrm{Ma}$ (Pardo-Casas \& Molnar, 1987) se han producido importantes deformaciones próximas al borde occidental, como la actual Cordillera de los Andes. Los acortamientos horizontales ligeramente oblicuos producidos reactivaron transpresionalmente las estructuras preexistentes en su antepaís de las Sierras Pampeanas y se han propagado por todo el continente sudamericano, incluso sobre su borde Atlántico (Cobbold et al., 1996 y 2005; Rossello \& Bordarampé, 2005). A partir de la influencia de la tectónica Andina que involucra al conjunto del continente sudamericano y en particular sobre discontinuidades preexistentes (Cobbold et al. 1996 y 2005) estos fallamientos normales lístricos de crecimiento (especialmente los que limitan por el Oeste a los rifts) fueron invertidos. La intensidad de estas reactivaciones se incrementan a medida que se aproximan a la Cordillera de los Andes y se interrelacionan más íntimamente con bloques de basamento cristalino que constituye su antepaís.

DISCUSIÓN Y CONCLUSIONES Las observaciones descriptas anteriormente, permiten enunciar los siguientes comentarios y conclusiones que contribuyen con la definición de nuevas hipótesis de trabajo para la región:

Continuidad austral del Alto Asunción La continuidad austral del Alto Asunción, tal como fue descripto en la Introducción, constituyó un motivo de diversas interpretaciones, sin embargo a partir de las descripciones realizadas precedentemente, se considera que la mejor alternativa es su conexión con el Arco 


\section{Río Grande (Figura 1).}

La información aportada por el Pozo Nogoyá x-1 (véase ubicación en Figura 6a), proporcionó un importante y novedoso control geológico para el subsuelo de la región mesopotámica (Fernández Garrasino, 1990). Este pozo insinuó un alto basamental asociado con el Alto Asunción y sugirió inicialmente su prolongación directamente hacia el sur (Fernández Garrasino, 1992a y 1992b). Luego Fernández Garrasino \& Vrba (1999 y 2000) a partir de mapeos estructurales sólo lo continúan hasta la porción austral de la provincia de Corrientes, pudiéndose de esta manera considerarlo como un alto subordinado de la DARG. Por ello, con un conocimiento mayor de la morfología del subsuelo de las provincias de Corrientes y Misiones se podrá ajustar con detalle esta conexión que podría determinar altos y bajos subordinados o relativos con respecto al DARG.

Control tectosedimentario de la DARG en las cuencas Paraná y Chacoparanense. La conformación de la DARG a partir del Paleozoico superior ha sido un elemento tectónico de primera magnitud en el desarrollo paleogeográfico que controló la depositación de las secuencias sedimentarias de las cuencas Paraná y de la Llanura Chacoparanense. A partir de entonces, las cuencas comenzaron a evolucionar más independientemente al punto de exhibir depocentros aislados pero cronoestratigráficamente equivalentes. De esta manera, la DARG constituye una estructura anticlinal con una anticulminación central que determina su geometría de silla de montar sobre la cual las secuencias exhiben secciones cronolitoestratigráficas condensadas (Figura 11).

Por lo tanto, se aprecia que el segmento septentrional de la DARG se encuentra seccionado por fosas aulacogénicas (una al norte del Alto de Apa y otra entre el espolón sur de ese alto y el Rift de Asunción), que constituyen conexiones marinas regionales con el protopacífico entre el Ordovícico Silúrico y el Devónico. Estas conexiones cortan a la DARG y comunican la cuenca Paraná con el océano Proto-Pacífico hasta el Devónico superior; luego no existen más en el Carbonífero, inclusive, con la inversión de depocentros en la cuenca Paraná (Assine, 1996). Un levantamiento de la DARG septentrional, en ese periodo, causa sucesivos ciclos de erosión en las unidades litoestratigráficas más antiguas y disloca la conexión marina de la cuenca Paraná en dirección SSO (entre la extremidad sur del Alto Asunción y el Arco Río Grande).

La subsidencia inicial en la Cuenca Paraná, correspondiente a la depositación de los estratos ordovícico- silúricos del Grupo Caacupé, fue condicionada por aulacógenos de dirección NW, con subsecuente fase de subsidencia térmica dando origen a la sineclise intracratónica (Fulfaro et al., 1982).

También, a partir de la correspondencia entre este tipo de altos, tanto en el continente sudamericano como en el africano, es posible propagar la misma deformación hacia porciones muy internas del sudoeste del Gondwana, tal como fuera descripto por Cobbold et al. (1991). En este sentido, también Zalan et al. (1990) señalaron que el comportamiento del Arco Asunción, probablemente a lo largo de su evolución geológica, corresponda a una respuesta flexural de la corteza a los movimientos orogénicos ocurridos sobre el margen occidental del Gondwana. $\mathrm{Al}$ respecto, se pueden reconocer y correlacionar temporoespacialmente los siguientes altos, localizados respectivamente en los continentes sudamericano y africano: Alto Río de la PlataKalahari, Alto Sierras Australes-El Cabo y Alto Ponta GrossaNamibia. Todos muestran historias tectosedimentarias contemporáneas y disposiciones subparalelas con el Arco Magmático Permo-Triásico de la Cordillera Frontal, según sus reconstrucciones paleogeográficas previas a la deformación Andina (Figura 12).

El reconocimiento de una tectónica compresiva permotriásica abre nuevos caminos para la comprensión de la evolución geotectónica y tectosedimentaria de la Cuenca Norte, y por correlación con sus restantes porciones de la Cuenca Paraná. Esto se hace aún más interesante en lo que respecta al arreglo espacial de los sistemas depositacionales y la actuación de altos internos (Isla Cristalina de Rivera) así como al entendimiento de algunas
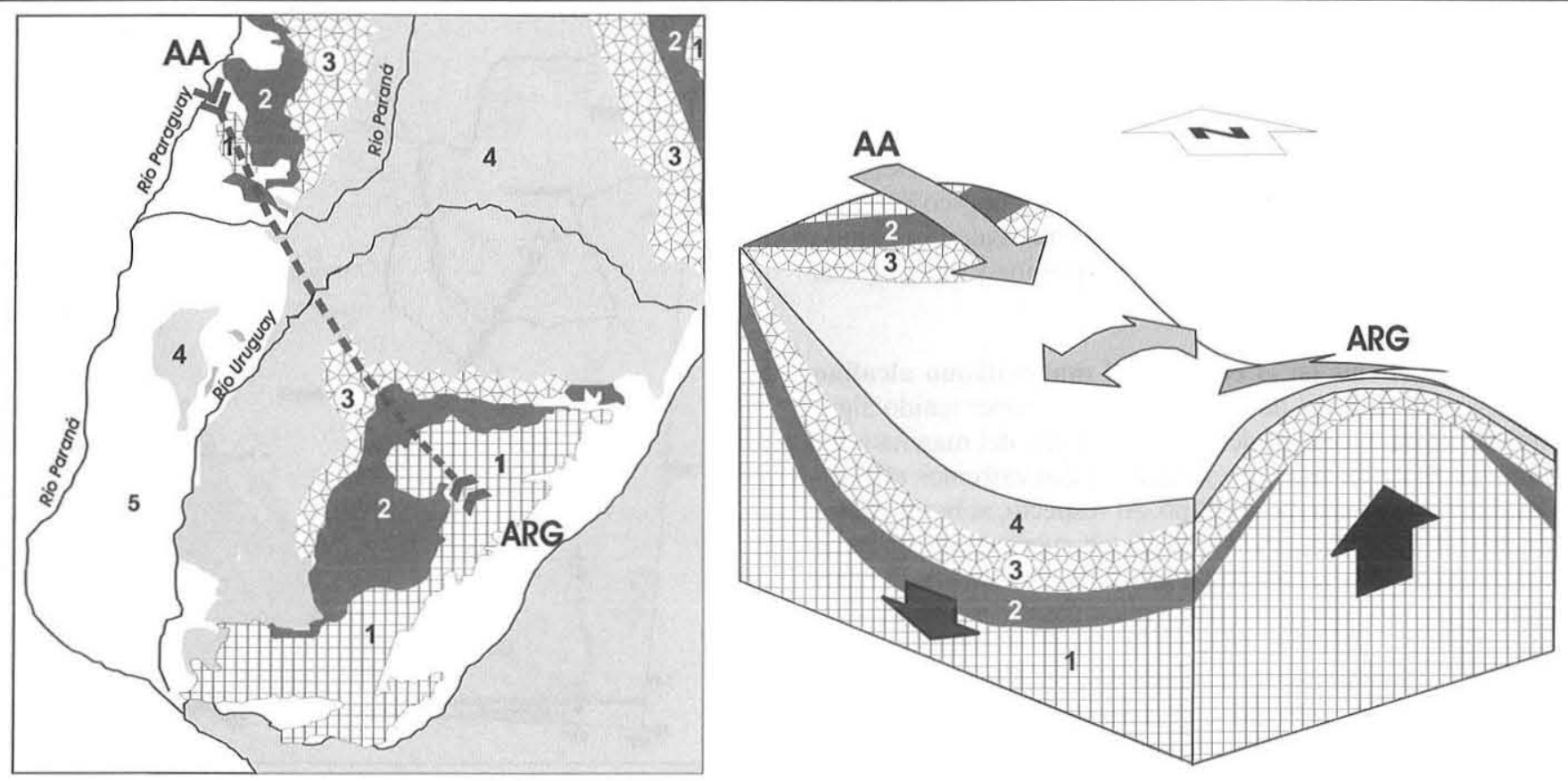

Figura 11. Izquierda: Bosquejo geológico de la DARG que muestra la continuidad entre los Altos de Asunción (AA) y Río Grande (ARG). Derecha: Esquema 3D de la DARG como una silla de montar: 1: Basamento precámbrico, 2: Paleozoico, 3 Basaltos F. Serra Geral, 4: Mesozoico. 


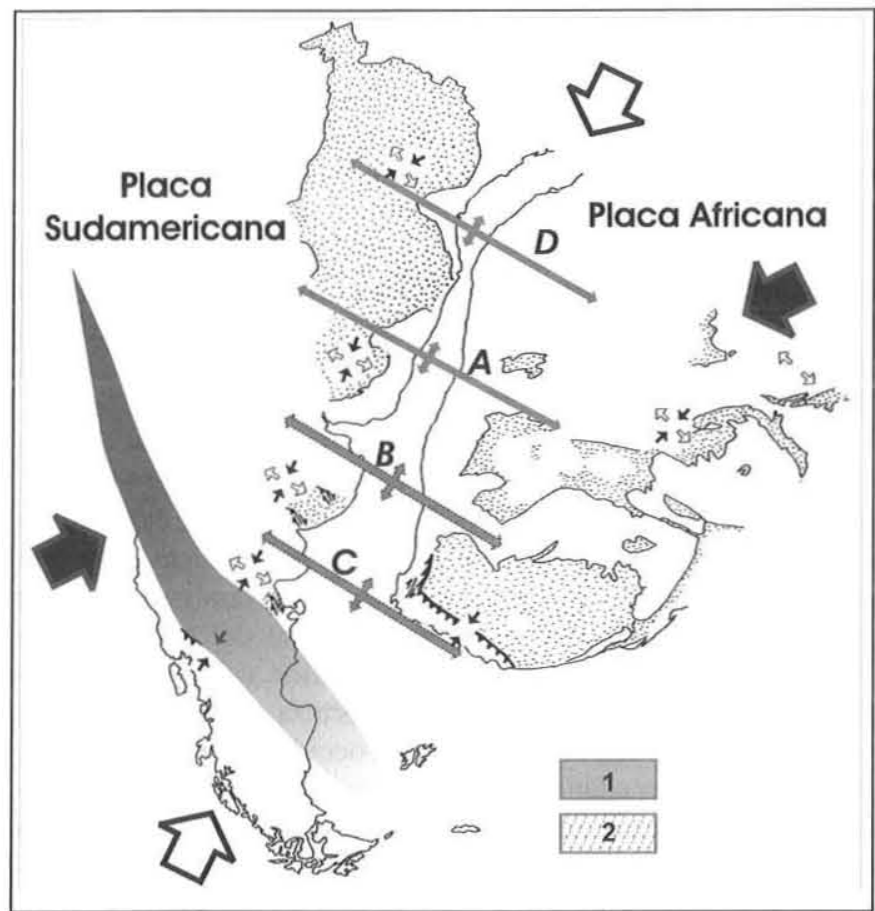

Figura 12. Esquema de la deformación Permo - Triásica en la porción SO del Gondwana donde se indican campos deformacionales medidos a partir de indicadores cinemáticos (pares de flechas pequeñas blancas abiertas: extensión y negras: compresión) superficiales (tomado de Cobbold et al., 1991). A) DARG, B) Alto Río de la Plata- Kalahari, C) Alto Sierras AustralesEl Cabo y D) Alto Ponta Grossa-Namibia. 1) Arco Magmático Permo-Triásico de la Cordillera Frontal, 2) Áreas cratónicas aflorantes. Las flechas negras indican la dirección de la compresión Permo-Triásica y las blancas la convergencia Andina Neógena.

omisiones estratigráficas que se verifican en varios sectores de la Cuenca Norte. Así, se permite mostrar el desarrollo del mar Irati-Mangrullo donde aparece limitado por el oeste en lo que podría ser la traza de la DARG.

Además, la distribución del mar Mangrullo asociada a las periferias de las Islas cristalinas de Rivera y Aceguá (Departamento de Cerro Largo) permite vincular con el Pérmico Superior (Kunguriano) ese levantamiento, ya que el mar Palermo - Fraile Muerto está presente hacia el oeste en Argentina y Uruguay (de Santa Ana, 2004).

Posibles influencias en el control del magmatismo alcalino La disposición regional de la DARG parece haber tenido alguna influencia en el control del emplazamiento del magmatismo alcalino presente en la región ya que sus dos extremos aflorantes exhiben intrusiones de este tipo. Al respecto, sobre el flanco occidental del Alto Asunción se conocen cuerpos de esta naturaleza cuyas edades varían desde los $255 \mathrm{Ma}$ hasta los $39 \mathrm{Ma}$ y el Arco Río Grande presenta otros semejantes con edades Cretácico superior - Terciario (Sonoki \& Garda, 1988; Riccomini et al., 2005). El magmatismo alcalino de tipo nefelinítico, típico de intraplaca, puede expresar una anomalía cortical de primera magnitud que facilitó y controló preferencialmente el ascenso de material mantélico en una zona diferencialmente adelgazada y/o en extensión.

Sin embargo, escapan a este contexto las muchas otras ocurrencias que están asociadas a otros bordes de la Cuenca Paraná $\mathrm{y}$ algunos cuerpos que presentan petrologías alcalinas de tipo adakitico más afines con contextos de subducción (Riccomini et al., 2005).

Por ello, una adecuada caracterización del vínculo temporoespacial de estos fenómenos alcalinos con la presencia de la DARG podría aportar guías prospectivas importantes en la detección de mineralizaciones con potencial económico relacionadas con este tipo de magmatismo, entre las que se destacan carbonatitas y kimberlitas (Fulfaro et al., 1997; Rossello et al., 2001).

Influencias sobre la geometría del Acuífero Guaraní (SAG). Las secuencias litoestratigráficas que constituyen el medio físico que soporta al SAG se desarrollan a lo largo de dos grandes ambientes geológicos separados por la DARG. Estos corresponden a los siguientes dos ámbitos geotectónicos (Figuras 13, 14).

a) La Cuenca Paraná, hacia el oriente, mejor expuesta y por lo tanto con un volumen mayor de estudios disponibles y b) La Llanura Chacoparanense y las diferentes cuencas sedimentarias que cubre, hacia el occidente, que obliga por sus escasos afloramientos a su descripción casi exclusivamente a partir de información del subsuelo (Chebli et al., 1999).

La intersección de la DARG con el fallamiento extensional paleozoico inferior dispuesto con rumbos NE que determina el Rift Central de la Cuenca Paraná, así como el fallamiento que

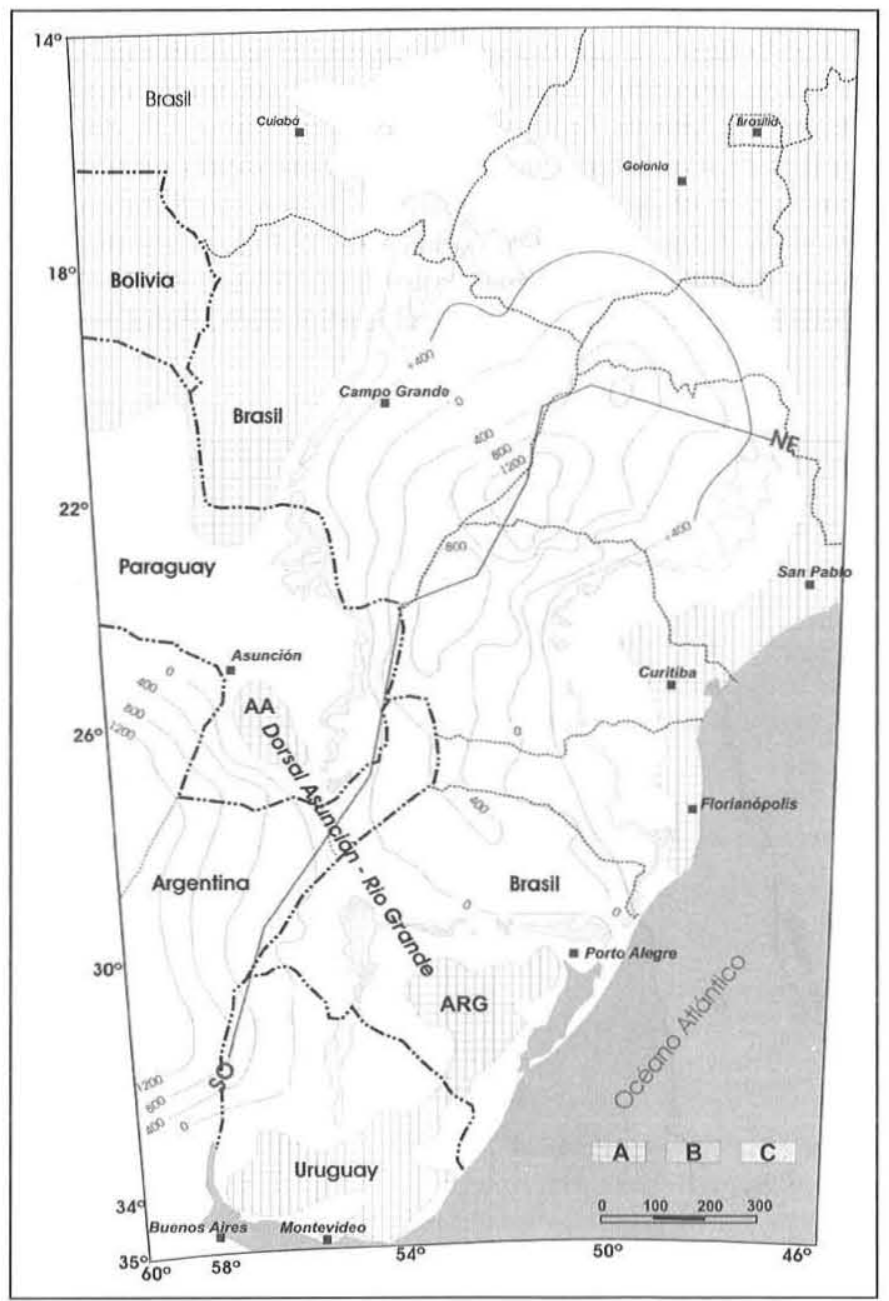

Figura 13. Mapa estructural del Acuifero Guarani (modificado de Araujo et al., 1999). A: Áreas de basamento, B: Afloramientos de unidades reservorio y $C$ : Sectores soterrados con curvas en metros. SW-NE sección estructural de la Figura 14. 


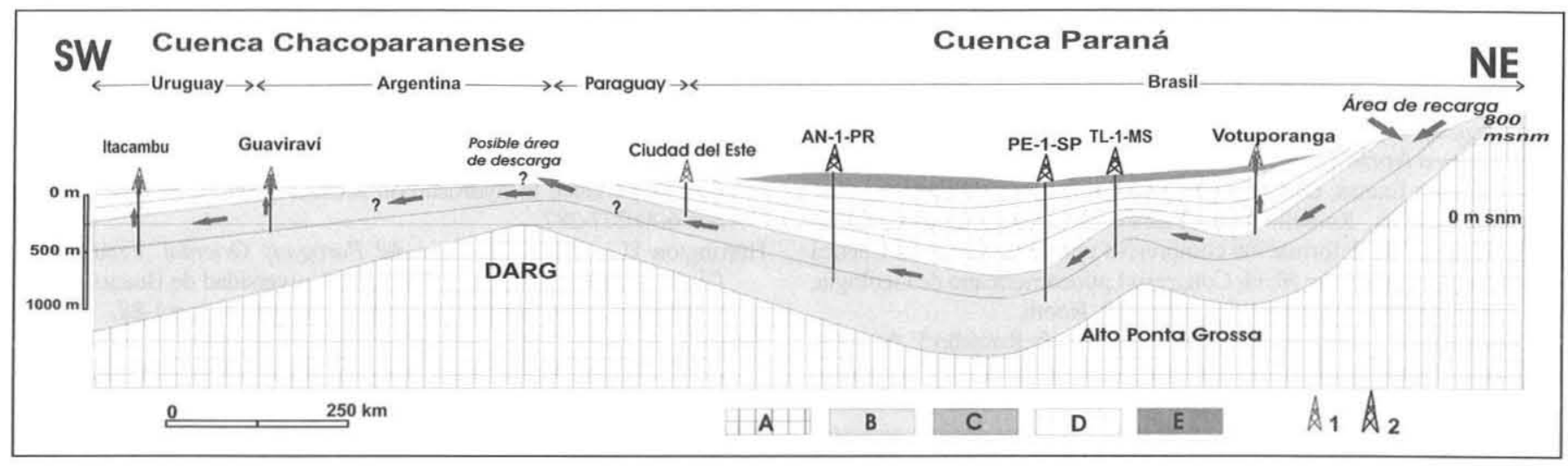

Figura 14. Sección estructural regional a través del SAG (modificado de Araujo et al., 1999). Para su localización véase la Figura 13. A: Basamento, B: Paleozoico indiferenciado, C: Sistema Acuifero Guarani, D: Basaltos Serra Geral, E: Grupo Baurú. 1: Pozos hidrogeológicos y 2: Pozos petroleros. Las flechas dentro del SAG indican direcciones preferenciales de escorrentia subterránea

se desarrolla por las provincias de Corrientes y Entre Ríos con rumbo subparalelo al Río Uruguay (Figura 5) resulta importante para la delimitación del área de ocurrencia del SAG a escala regional con real potencial exploratorio y productivo.

El SAG en términos generales está constituido por unidades sedimentarias y volcánicas variablemente permeables que involucran desde el Paleozoico Superior alto hasta el Cretácico, y que exhibe una dirección de escorrentía de las aguas subterráneas regional preferencial desde el NE hacia el SW. De este modo, la DARG podría actuar como una barrera subterránea al flujo regional del SAG hacia el SW que determinaría que los niveles freáticos alcancen la superficie y generen la presencia de los pantanales y humedales gigantescos de los Esteros del Iberá, en la provincia de Corrientes, Argentina. Sin embargo, estas suposiciones deberán ser consolidadas y eventualmente comprobadas con estudios hidrogeológicos específicos.

A partir de una sección estructural regional dispuesta en dirección aproximada SW-NE es posible visualizar la tendencia topográfica regional hacia un nivel de base localizado en Argentina y la relación del depocentro que constituye a la Cuenca Paraná y con la DARG (Figura 14).

Agradecimientos Se desea dejar constancia de nuestro agradecimiento a los innumerables colegas que contribuyeron generosa y desinteresadamente con la realización del presente trabajo que constituye otro ejemplo de integración profesional multinacional para abarcar un tema de interés común que por su dimensión y localización geográfica hubiera sido imposible de lograr. Se agradece el apoyo brindado por la Universidad de Buenos Aires (Proyectos de Investigación Bienales Renovables Programación Científica 2004 -2007, EX 272) y la Universidad Nacional de San Luis (Proyecto C y T No 349001). Los árbitros de la revista (Dr. Elson Paiva de Oliveira y otro anónimo) aportaron muy valiosas observaciones y comentarios que mejoraron notablemente el contenido original del manuscrito.

\section{Referências}

Almeida F.F.M. 1967. Origem e evolução da plataforma brasileira. Rio de Janeiro, DNPM/DFPM, Boletim 241, 36 pp.

Araujo L.M., França A.B., Potter P.E. 1999. Hydrogeology of the Mercosul aquifer system in the Paraná and Chaco-Paraná Basins, South America, and comparison with the Navajo-Nugget aquifer system, USA. Hidrogeology Journal, 7:317-336.

Assine M.L. 1996. Aspectos da estratigrafia das seqüencias pré-carboníferas da Bacia do Paraná no Brasil. Tese de Doutoramento, Instituto de Geociências, Universidade de São Paulo, São Paulo, 207 p.

Bergamaschi S. 1999. Análise estratigráfica do Siluro-Devoniano (Formações Furnas e Ponta Grossa) da Sub-Bacia de Apucarana, Bacia do Paraná. Tese de Doutoramento, Instituto de Geociências, Universidade de São Paulo, S. Paulo, 276 pp.

Chebli G.A., Tófalo O.R.,Turazzini G.E. 1989. Mesopotamia. In: G.A. Chebli \& L.A. Spalletti (eds.) Cuencas Sedimentarias Argentinas. Instituto Superior de Correlación Geológica 6, Universidad Nacional de Tucumán. Serie Correlación Geológica, pp.: 65-78

Chebli G.A., Mozetic M.E., Rossello E.A., Bühler M. 1999. Cuencas sedimentarias de la llanura chacopampeana. In: R. Caminos (ed.) Geología Argentina. Subsecretaría de Minería de la Nación, Instituto de Geologia y Recursos Minerales, Anales 29, pp.: 627-644.

Chemale Jr. F. 2002. Evolução geológica do Escudo Sul-Rio-Grandense. In: M. Holz \& L.F. De Ros (eds.) Geología do Rio Grande do Sul, CIGO. Universidade Federal do Rio Grande do Sul, pp.:13-52.

Christie-Blick N. \& Biddle K.T. 1985. Deformation and basin formation along strike-slip faults. In: K.T. Biddle \& N. Christie-Blick (eds.). Strike-slip deformation, basin formation and sedimentation. Society Economic Paleontologists Mineralogists, Special Publication 37, pp.:1-34.

Clérici A.M., Suguio K., Fulfaro V.J. 1986. Reavaliação da Geologia do Paraguai Oriental. In: SBG, Cong. Brasil. Geologia, 34, Atas, v. 1, p. 163-176.

Cobbold P.R., Rossello E.A., Gapais D. 1991. Partitioning of transpressive motions within a sigmoidal foldbelt: the Variscan Sierras Australes, Argentina. J. Struc. Geol. 13(7):743-758.

Cobbold P.R., Szatmari P., Lima C., Rossello E.A, 1996. Cenozoic deformation across South America: Continent-wide data and analogue models. In: ORSTOM-Géosciences Rennes, International Symposium on Andean Geodynamics, 3, Saint Maló, Ext. Abst?, v. 1, pp.: 21-24.

Cobbold P.R., Rossello E.A, Roperch P., Arriagada C., Gómez L.A., Lima C. 2005. Distribution, timing and causes of the Andean deformation across South America. In: A. Ries, R. Graham, R. Butler (eds.). Geol. Soc. London. Special Volumen. In press.

Comin-Chiaramonti P., Civetta L., Petrini R., Piccirillo E., Bellieni G, Censi P., Bitschene P., Castillo A., Velázquez J. 1990. Tertiary nephelinitic magmatism in eastern Paraguay: petrology, $\mathrm{Sr} / \mathrm{Nd}$ isotopes and genetic relationships with associated spinel-peridotite xenoliths. Euro. J. Mineral. 3:507-525.

Crowell J. \& Frakes L. 1975. The Late Paleozoic glaciation. In: K. Cam- 
pbell (ed.) Gondwana Geology. 3rd Gondwana Symposium Proceedings. Australia National University Press pp.: 313-331.

De Santa Ana H. 2004. Análise estratigráfica das seqüências permotriássicas e jurocretáceas da Bacia Chaco-paranense uruguaia ("Cuenca Norte"). Tese de Doutoramento, Instituto de Geociências e Ciências Exatas, Universidade Estadual Paulista, 315 pp.

De Santa Ana H., Rossello E.A., Fulfaro V.J., Veroslavsky G. 2001. Evidencias de deformación compresiva permotriásica en la Cuenca Norte (Uruguay). In: SUG, Congreso Latinoamericano de Geología, 11 \& Congreso Uruguayo, 3, Actas, Cd- Room.

De Santa Ana H., Veroslavsky G., Fulfaro V.J. \& Rossello E.A. 2006. Cuenca Norte: evolución tectónica y sedimentaria del Carbonífero - Pérmico. In: G. Veroslavsky, M. Ubilla \& S. Martinez (eds.) Cuencas Sedimentarias de Uruguay: geología, paleontologia y recursosnaturales - Paleozoico, Dirac, pp.: 209-244.

Fernández V.V. 1992. Provincia alcalina central, Paraguai centro-oriental: aspectos tectónicos, petrográficos e geocronológicos. Dissertação de Mestrado, Instituto de Geociências, Universidade de São Paulo, São Paulo, 119 p.

Fernández Garrasino C.A. 1990. La sucesión estratigráfica del pozo YPF Nogoyá 1, provincia de Entre Ríos. In: Reunión Argentina de Sedimentologia, 3, San Juan, Actas, v. 1, p. 125-129.

Fernández Garrasino C.A. 1992a. El "Alto de Asunción" en la Mesopotamia Argentina. In: AGA, Reunión Argentina de Sedimentología, 4, La Plata, Actas, v.1, p. 191-198.

Fernández Garrasino C.A. 1992b. El "Alto de Asunción" en la Mesopotamia Argentina. Ensayo de división subregional. Bol. Inform.Petrol. 9(31):15-31.

Fernández Garrasino C.A. 1993. Supuestos registros gondwánicos en el subsuelo de la Provincia de Misiones, Argentina. In: Reunión del Grupo Argentino de Trabajo del Proyecto Pangea Comunicaciones, 2, San Juan, Actas (inédito).

Fernández Garrasino C.A \& Vrba A. 1999. Estructura del tope de la Formación Serra Geral (Neojurásico Eocretácico) en la Mesopotamia argentina y adyacencias. In: Congreso Geológico Argentino, 14, Salta, Actas, v. 1, pp.: 185-188.

Fernández Garrasino C.A \& Vrba A. 2000. La Formación Paraná: aspectos estratigráficos y estructurales de la región chacoparanense. In: F. Aceñolaza \& R. Herbst (ed.) El Neógeno de Argentina. Facultad de Ciencias Naturales e Instituto Miguel Lillo de la Universidad Nacional de Tucumán, Instituto Superior de Correlación Geológica, Serie 14, pp.:139-145.

Fernández Garrasino C.A., Lafitte G., Villar H. 2005. Cuenca Chacoparanaense. In: G.A. Chebli, L.A. Spalletti, J.S. Cortiñas, L. Legarreta, E.L. Vallejo (eds.) Frontera Exploratoria de la Argentina. Congreso de Exploración y Desarrollo de Hidrocarburos, 6, Instituto Argentino del Petróleo, Cap. 5, pp.: 97-114.

França A.B., Milani E.J., Schneider R.L, López Paulsen O., López Puglissi J.M., Suárez R., de Santa Ana H., Wiens F., Ferreiro O., Rossello E.A., Bianucci H.A., Flores F.F.A., Vistalli M.C., Fernández Seveso F., Fuenzalida R.P., Muñoz N. 1995. Phanerozoic correlation in Southern South America. In: A.J. Tankard, R. Suarez Souco, H.J. Welsink (eds.). Petroleum basins of South America. Amer. Assoc. Petrol. Geolog., Memoir 62, pp.: 129-161.

Fulfaro V.J. 1996. Geology of Eastern Paraguay. In: P. Comin-Chiaramonti \& C.B. Gomes (eds.). Alkaline magmatism in central-eastern Paraguay, relationships with coeval magmatismo in Brazil. EDUSP/ FAPESP, São Paulo, pp.:17-29.

Fulfaro V.J. \& Perinotto J.A.J. 1994. Geomorfologia do Estado do Mato Grosso do Sul e o arcabouço estrutural. In: SBG, Congresso Brasileiro de Geologia, 38, Camboriú/SC, Boletim Resumo expandido, p.197-198.

Fulfaro V.J. \& Perinotto J.A.J. 1995. Ciclos de erosão da margem ocidental da Bacia do Paraná, Mato Grosso do Sul e Paraguai. In: SBG, Simpósio de Geologia do Sudeste, 4, Águas de São Pedro/SP, Boletim Resumo expandido, p.63.

Fulfaro V.J. \& Perinotto J.A.J. 1996. Paleozóico da Bacia Sedimentar do Paraná no Centro-Oeste Brasileiro. Rio Claro, Relatório Final del Proceso FAPESP N 93-3156-6. Inédito, 156 p.

Fulfaro V.J., Saad A.R., Santos M.V., Vianna R.B. 1982. Compartimentação e evolução tectônica da Bacia do Paraná. Rev. Brasil. Geoc. 12(4):590-611.
Fulfaro V.J., Saad A.R., Perinotto J.A., Etchebehere M.L. \& Veroslavsky G. 1997. Paraná Basin: Mineral Resources Potential in Brazil, Uruguay and Paraguay. Inter: Geol. Rev. 30(8):703-722.

Gohrbandt K.H.A. 1992. Paleozoic paleogeographic and depositional developments on the central proto-Pacific margin of Gondwana: their importance to hydrocarbon accumulation. J. S. Amer: Earth. Sci. 6(4):267-287.

Harrington H.J. 1950. Geología del Paraguay Oriental. Facultad de Ciencias Exactas, Físicas y Naturales Universidad de Buenos Aires, Contribuciones Científicas Serie E (Geología), v. 1, p.1-82.

Herbst R. \& Santa Cruz J. 1985. Mapa Litoestratigráfico de la Provincia de Corrientes. Universidad Nacional del Nordeste, d'Orbignyana, v. 2, p. $1-50$.

Jones J.P. 1985. The southern border of the Guaporé Shield in western Brazil and Bolivia: an interpretation of its geologic evolution. Precambrian Research, 28:111-135.

López-Gamundi O.R. \& Rossello E.A. 1997. Common evolutionary pattern along the Samfrau geosyncline: the Sauce Grande Basin-Ventana foldbelt (Argentina) and Karoo Basin-Cape foldbelt (South Africa) revisited. Geol. Rundschau 86(4):819-834.

López-Gamundí O.R., Conaghan P.J., Rossello E.A., Cobbold P.R. 1995. The Tunas Formation (Permian) in the Sierras Australes Foldbelt, east central Argentina: evidence for syntectonic sedimentation in a foreland basin. J. S. Amer: Earth Scie. 8(2):129-142.

Malumián N., Nullo F.E., Ramos V.A. 1983. The Cretaceous of Argentina, Chile, Paraguay and Uruguay. In: M. Moullade \& A.E.M. Nairn (eds.) The Phanerozoic Geology of the World. II- The Mesozoic Basins, Elsevier, pp.: 265-304.

Milani E.J. 1997. Evolução tectono-estratigráfica da Bacia do Paraná e seu relacionamento com a geodinâmica fanerozóica do Gondwana sul-ocidental. Tese de Doutoramento, Instituto de Geociências, Universidade Federal do Rio Grande do Sul, Porto Alegre, 255p.

Milani E.J. 2004. Comentários sobre a origem e evolução tectônica da Bacia do Paraná, In: V. de Mantesso-Neto, A. Bartorelli, C.D. Ré Carneiro \& B.B de Brito Neves BB (Orgs). Geologia do Continente Sul-Americano: evolução da obra de Fernando Flávio Marques de Almeida. Beca Ed., pp.: 265-279.

Nielsen T.H. \& Sylvester A. G. 1995. Strike-slip basins. In: C.J. Busby \& R.V. Ingersoll (eds.) Tectonics of sedimentary basins. Blackwell Science, Cambridge, 549 pp.

Oelofsen B. \& Araújo D.C. 1987. Mesosaurus tenuidens and Sterosternum tumidum from the Permian Gondwana of both southern Africa and South America. S. African J. Science 83: 370-372.

Padula E. \& Mingramm A. 1968. Estratigrafia, distribución y cuadro geotectónico-sedimentario del "Triásico" en el subsuelo de la llanura Chaco-Paranense. In: Jornadas Geológicas Argentinas, 3, Buenos Aires, Actas, v.1, p. 291-331.

Palmieri J. \& Velázquez J. 1982. Geología del Paraguay. Colección apoyo a Cátedra, Serie Ciencias Naturales. Ediciones NAPA, 65 p.

Pardo-Casas F. \& Molnar P. 1987. Relative motion of the Nazca (Farallón) and South American Plates since Late Cretaceous time. Tectonics 6:233-248.

Peate D.W. 1997. The Paraná-Etendeka Province. In: J.J. Mahoney \& M.F. Coffin (eds.) Large igneous provinces: continental, oceanic and planetary flood volcanism. Geophysical Monograph 100, pp.: 217-245.

Pereira E. 2000. Evolução tectono-sedimentar do intervalo Ordoviciano-Devoniano da Bacia do Paraná com ênfase na sub-bacia Alto Garças e no Paraguai Oriental. Tese de Doutoramento, Instituto de Geociências, Universidade de São Paulo, S. Paulo, 276p.

Pezzi E. \& Mozetic M.E. 1989. Cuencas sedimentarias de la región chacoparanense. In: G.A. Chebli \& L.A. Spalletti (ed.) Cuencas Sedimentarias Argentinas. Universidad Nacional de Tucumán, Instituto Superior de Correlación Geológica (Tucumán) Serie Correlación Geológica v.6, p. 65-77.

Putzer H. 1962. Geologie von Paraguay. Beiträge zur Regionalen Geologie der Erde, Gebrüder Borntraeger (Berlin), 182 pp.

Redmond J.L. 1979. Parana Basin, Paraguay. Tectonics and hydrocarbon potential. In: American Geological Congress, 4, Trinidad \&Tobago, Actas, p. 1-8.

Riccomini C. \& Fernández Velázquez V. 1999. Superfície estriada por geleira neopaleozoica no Paraguai oriental. Rev. Bras. Geo., 
31(4):661-662.

Riccomini C., Velázquez V.F., Gomes C.B. 2005. Tectonic control of the Mesozoic and Cenozoic alkaline magmatism in the central southerstern Brazilian Platform. In: Comin-Chiaramonti P. \& Gomes C.B. (eds.) Mesozoic to Cenozoic alkaline magmatism in the Brazilian Platform. Edusp, São Paulo, pp.: 33-55

Rossello E.A. \& Bordarampé C.P. 2005. Las Lomadas de Otumpa: nuevas evidencias cartográficas de deformación neotectónica en el Gran Chaco (Santiago del Estero, Argentina). In: Congreso Geológico Argentino, 15, La Plata, Argentina, Actas, CDroom.

Rossello E.A. \& López de Luchi M.G.. 2005. The Trans-Argentine Corridor (Central Argentina). In: R. Pankurst \& G. Veiga (eds) $A$ Cretaceous intracontinental riffing associated to the Gondwana break-up. Gondwana 12. Mendoza, Argentina, Academia Nacional de Ciencias, 313p.

Rossello E.A. \& Mozetic M.E. 1999. Caracterización estructural ysignificado geotectónico de los depocentros Cretácicos continentales del Centro-Oeste Argentino. In: Simpósio sobre o Cretáceo do Brasil, 5, \& Simposio sobre el Cretácico de América del Sur, 1, Serra Negra, Brasil, Actas, 107-113.

Rossello E.A., Veroslavsky G., De Santa Ana H. 2001. Influencias del lineamiento transtensivo Santa Lucía - Aiguá - Merín sobre el emplazamiento del magmatismo alcalino cretácico del Cratón del Río de la Plata (Uruguay): aportes a la prospección diamantífera. Rev. Bras. Geo., 31(2):163-168.

Rossello E.A., Massabie A.C., López-Gamundí O.R., Cobbold P.R. \& Gapais D. 1997. Late Paleozoic transpression in Buenos Aires and northeast Patagonia ranges, Argentina. J. South Amer: Earth Scien., $10(5-6): 389-402$.

Russo A., Ferello R., Chebli G. 1979. Llanura Chaco Pampeana. In: Simposio de Geología Regional Argentina, 2, . Academia Nacional de Ciencias (Córdoba), Actas, v.1, p. 139-183.

Santos P.R., Rocha-Campos A.C., Canuto J.R. 1996. Patterns of Late Palaezoic deglaciation in the Paraná Basin, Brazil. Palaegeography, Palaeoclimatology, Palaeocology, 125:165-184.

Sanford R. \& Lange F. 1960. Basin study approach to oil evaluation of Paraná miogeosyncline, South Brazil. Amer. Assoc. Petrol. Geolog. Bulletin 44(8): 1316-1370.

Sonoki I.K. \& Garda G.M. 1988. Idades K-Ar de rochas alcalinas do Brasil Meridional e Paraguai oriental: compilacão e adaptação as novas constantes de decaimento. Boletim IG-USP Série Cientifica, 19:63-85.

Tankard A., Uliana M., Welsink H., Ramos V.A., Turic M., Barros França A., Milani E., Brito Neves B. de, Eyles N., Skarmeta J., Santa Ana H., Wiens F., Cirbian M., Lopez Paulsen O., Germs G., Wit M. de, Machacha T., Miller R. Mc G. 1995. Structural and tectonic controls of basin evolution in Southwestern Gondwana during the
Phanerozoic. In: A.J.Tankard, R. Suárez Soruco, H.J. Welsink (Eds.) Petroleum Basins of South America. Amer. Assoc.Petrol. Geolog., Memoir 62, pp.: 5-52.

Uliana M.A. \& Biddle K. 1988. Mesozoic-Cenozoic paleogeographic and geodynamic evolution of southern South America. Rev. Bras. Geoc., 18(2):172-190.

Urien C.M. 2003. Present and future petroleum provinces of Southern South America. In. M.W. Downey, J.C. Theet, W.A. Morgan (eds.) Petroleum provinces of the twenty-.rst century. Amer. Assoc. Petrol. Geolog. Memoir 74, pp.: 373-402.

Urien C.M \& Zambrano J.J. 1996. Estructura del margen continental. In: Congreso Geológico Argentino, 13, \& Congreso de Exploración de Hidrocarburos Geología y Recursos Naturales de la Plataforma Continental Argentina, 3, Buenos Aires, Actas, p. 29-65.

Urien C.M., Zambrano J.J., Martins L.R. 1981. The basins of south-eastern South America (Southern Brazil, Uruguay and eastern Argentina), including the Malvinas Plateau and southern South Atlantic paleogeographic evolution. In: (eds.) Cuencas sedimentarias del Jurásico y Cretácico de América del Sur. Comité Sudamericano del Jurásico y Cretácico, Buenos Aires, v.1, p. 45-125.

Urien C.M., Zambrano J.J., Yrigoyen M.R. 1995. Petroleum basins of southern South America: an overview. In: A.J. Tankard, R. SuárezSoruco, H.J. Welsink (eds.) Phanerozoic correlation in Southern South America. Petroleum basins of South America. Amer. Assoc. Petrol. Geolog. Memoir 62, pp.: 63-77.

Webster R.E., Chebli G.A., Fritz Fischer J., 2004. General Levalle basin, Argentina; a frontier lower Cretaceous rift basin. Amer: Assoc. Petrol. Geolog. Bulletin, 88(5):627-652.

Wiens F. 1995. Phanerozoic tectonics and sedimentation in the Chaco Basin of Paraguay, with comments on hydrocarbon potential. In: A.J. Tankard, R. Suárez Soruco, H.J. Welsink (eds.) Petroleum Basins of South America. Amer. Assoc. Petrol. Geolog. Memoir 62, p. 185205.

Williams K.E. 1995. Tectonic subsidence analysis and paleozoic paleogeography of Gondwana. In: A.J. Tankard, R. Suárez Soruco, H.J. Welsink (eds.) Petroleum Basins of South America. Amer. Assoc. Petrol. Geolog. Memoir 62, p. 79-100.

Zalan P.V., Wolff S., Astol. M.M, Vieira I.S,. Conceição J.C, Appi V.T, Neto E.V., Cerqueira J., Marques A. 1990. The Paraná Basin, Brazil. In: M.W Leighton, D.R Kolata, D.F. Oltz, J.J. Eidel (eds.). Interior cratonic basins. Amer. Assoc. Petrol.Geolog. Memoir 51, p. 681708.

Manuscrito AE027 Aprovado em 06 de outubro de 2006 